CrossMark

Cite as

Nano-Micro Lett. (2019) 11:3

Received: 15 October 2018 Accepted: 10 December 2018 Published online: 9 January 2019 (C) The Author(s) 2019

\section{Coral-Like Yolk-Shell-Structured Nickel Oxide/Carbon Composite Microspheres for High-Performance Li-Ion Storage Anodes}

\author{
Min Su Jo ${ }^{1}$, Subrata Ghosh ${ }^{2}$, Sang Mun Jeong ${ }^{2}$, Yun Chan Kang ${ }^{3 凶}$, Jung Sang Cho ${ }^{1 凶}$ \\ $\bowtie$ Yun Chan Kang, yckang@korea.ac.kr; Jung Sang Cho, jscho@cbnu.ac.kr \\ 1 Department of Engineering Chemistry, Chungbuk National University, Chungbuk 361-763, \\ Republic of Korea \\ 2 Department of Chemical Engineering, Chungbuk National University, Chungbuk 361-763, \\ Republic of Korea \\ 3 Department of Materials Science and Engineering, Korea University, Anam-Dong, Seongbuk-Gu, \\ Seoul 136-713, Republic of Korea
}

\title{
HIGHLIGHTS
}

- Coral-like yolk-shell-structured nickel oxide/carbon composite microspheres were synthesized.

- Phase separation and polystyrene nanobead decomposition affected the structure formation.

- Coral-like yolk with interconnected mesopores provided excellent Li-ion storage properties.

\begin{abstract}
In this study, coral-like yolk-shell-structured NiO/C composite microspheres (denoted as CYS-NiO/C) were prepared using spray pyrolysis. The unique yolk-shell structure was characterized, and the formation mechanism of the structure was proposed. Both the phase separation of the polyvinylpyrrolidone and polystyrene (PS) colloidal solution and the decomposition of the size-controlled PS nanobeads in the droplet played crucial roles in the formation of the unique coral-like yolk-shell structure. The CYS-NiO/C microspheres delivered a reversible discharge capacity of $991 \mathrm{mAh} \mathrm{g}^{-1}$ after 500 cycles at the current density of $1.0 \mathrm{~A} \mathrm{~g}^{-1}$. The discharge capacity of the CYS-NiO/C microspheres after the 1000th cycle at the current density of $2.0 \mathrm{~A} \mathrm{~g}^{-1}$ was $635 \mathrm{mAh} \mathrm{g}^{-1}$, and the capacity retention measured from the second cycle was $91 \%$. The final discharge capacities of the CYS-NiO/C microspheres at the current densities of 0.5 , 1.5, 3.0, 5.0, 7.0, and 10.0 $\mathrm{A} \mathrm{g}^{-1}$ were 753, 648, 560, 490, 440, and $389 \mathrm{mAh} \mathrm{g}^{-1}$, respectively. The synergetic effect of the coral-like yolk-shell structure with well-defined interconnected mesopores and highly conductive carbon resulted in the excellent $\mathrm{Li}^{+}$-ion storage properties of the CYS-NiO/C microspheres.
\end{abstract}

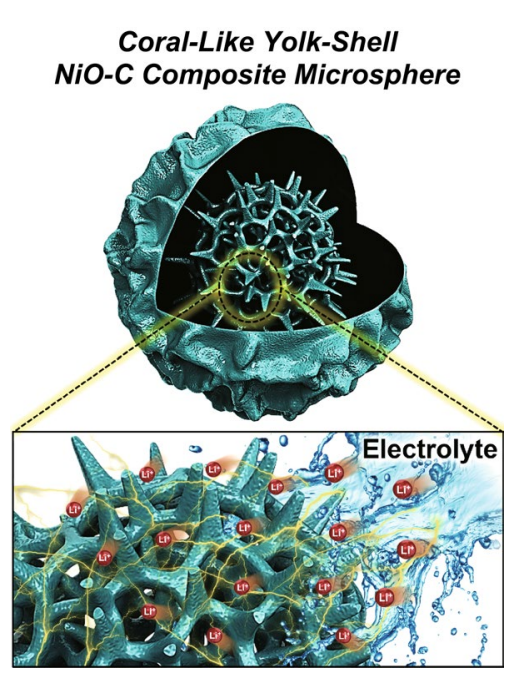

KEYWORDS: Yolk-shell; Nickel oxide; Carbon composite; Anode materials; Spray pyrolysis; Lithium-ion batteries 


\section{Introduction}

With the rapid increase in the energy demand, lithium-ion batteries (LIBs) have gained immense attention as next-generation energy storage devices and sources of vehicle energy [1-7]. Hence, in order to improve the performance of LIBs, it is imperative to develop innovative anode materials [8-11]. Transition metal oxides (TMOs) have been recognized as appropriate anode materials owing to their higher theoretical capacities as compared to that of graphite, high abundance, and chemical stability [12-16]. However, the drastic capacitance fading of TMOs owing to their large volume expansion during cycling has hindered their application as LIB anodes [17-21]. Therefore, various TMO nanostructures including nanoparticles, nanowalls, nanotubes, nanofibers, and nanoflakes have been extensively studied [22-28]. Recently, the yolk-shell structure materials have been used to improve the anode performance of LIBs [29-34]. For example, Zhang et al. synthesized an iron oxide/carbon yolk-shell structure by carbonizing $\alpha-\mathrm{Fe}_{2} \mathrm{O}_{3} / \mathrm{SiO}_{2} /$ poly-dopamine composite nanoparticles followed by the removal of the $\mathrm{SiO}_{2}$ layer using $\mathrm{NaOH}$. The $\mathrm{Fe}_{2} \mathrm{O}_{3}$ /carbon yolk-shell structure exhibited a high reversible capacity of $810 \mathrm{mAh} \mathrm{g}^{-1}$ at $0.2 \mathrm{C}$ rate and an excellent cycling stability while maintaining a capacity of $790 \mathrm{mAh} \mathrm{g}^{-1}$ after 100 cycles [32]. Yu et al. also prepared yolk-shell Ni-Co mixed oxide nanoprisms through simple thermal annealing of Ni-Co precursor particles in air. These nanoprisms exhibited a reversible capacity of $1029 \mathrm{mAh} \mathrm{g}^{-1}$ after 30 cycles at $200 \mathrm{~mA} \mathrm{~g}^{-1}$ [33]. Furthermore, Kim et al. integrated $\mathrm{N}$-doped carbon in the hollow space between the yolk and the shell to achieve high capacity, accommodate volume change, improve electrical conductivity, and form a stable solid-electrolyte interphase (SEI) layer [34].

However, although yolk-shell structures with various compositions have been studied thus far, their long-term cycle properties are unsatisfactory for practical applications owing to their intrinsic low structural stability. An effective approach to overcome this limitation is to make TMO composites with carbonaceous materials. However, it is difficult to prepare yolk-shell-structured TMO/carbon hybrids using traditional synthesis methods. Therefore, the uniform composition of carbon and TMO and their even distribution in both the yolk and shell are quite challenging and have not been studied before.
In this study, we proposed a novel facile method for the synthesis of yolk-shell-structured TMO/carbon hybrid microspheres. The yolk had a coral-like structure with interconnected mesopores. Coral-like yolks shorten the $\mathrm{Li}^{+}$-ion diffusion path, facilitating the penetration of the electrolyte into the yolk during cycling. In addition, yolk-shell carbon composites can expand freely and hence show a highly stable SEI at the surface. Owing to the highly stable SEIs, such composites show excellent $\mathrm{Li}^{+}$-ion storage properties. Based on this concept, we synthesized coral-like yolk-shell-structured $\mathrm{NiO} / \mathrm{C}$ composite microspheres via a one-pot spray pyrolysis process and a subsequent heat treatment. During the spray pyrolysis, polyvinylpyrrolidone (PVP) in the droplet partially phase-separated from the polystyrene (PS) colloidal solution and migrated outward, and interconnected mesopores were formed owing to the decomposition of PS. The subsequent thermal contraction of the inner part of the composite at high reaction temperatures during the spray pyrolysis process resulted in the formation of unique corallike yolk-shell-structured $\mathrm{NiO} / \mathrm{C}$ composite microspheres. The resulting $\mathrm{NiO} / \mathrm{C}$ composite microspheres showed an ideal structure, and their long-term cycling and rate performances were superior to those of the other NiO-based nanomaterials with various morphologies reported till date.

\section{Experimental Section}

\subsection{Sample Preparation}

Coral-like yolk-shell-structured metal oxide/C composite microspheres were prepared via one-pot spray pyrolysis. First, the NiO-Ni-C composite microspheres with the corallike yolk-shell structure (denoted as CYS-Ni/NiO/C) were directly prepared by spray pyrolysis using a $0.2 \mathrm{M}$ aqueous spray solution of nickel nitrate hexahydrate $\left[\mathrm{Ni}\left(\mathrm{NO}_{3}\right)_{2} \cdot 6 \mathrm{H}_{2} \mathrm{O}\right.$, Daejung, 97\%], $20 \mathrm{~g} \mathrm{~L}^{-1}$ of PVP [ $\left(\mathrm{C}_{6} \mathrm{H}_{9} \mathrm{NO}\right), \mathrm{M}_{\mathrm{w}} 40,000$, Daejung], and $20 \mathrm{~g} \mathrm{~L}^{-1}$ of PS nanobeads ( $40 \mathrm{~nm}$ ). The sizecontrolled PS nanobeads ( $40 \mathrm{~nm}$ ) were synthesized using an emulsifier-free emulsion polymerization method. The spray pyrolysis system used in this study is shown in Fig. S1. In the spray pyrolysis process, droplets were generated with the aid of a $1.7 \mathrm{MHz}$ ultrasonic spray generator consisting of six vibrators. Subsequently, the droplets were transferred 
to a quartz reactor (length $=1200 \mathrm{~nm}$ and diameter $=50 \mathrm{~nm}$ ) by $\mathrm{N}_{2}$ gas (carrier) at a flow rate of $10 \mathrm{~L} \mathrm{~min}^{-1}$. During the spray pyrolysis process, the reactor temperature was maintained at $700{ }^{\circ} \mathrm{C}$. After the spray pyrolysis process, the asprepared microspheres $(\mathrm{CYS}-\mathrm{Ni} / \mathrm{NiO} / \mathrm{C})$ were post-treated at $250{ }^{\circ} \mathrm{C}$ at a heating rate of $5{ }^{\circ} \mathrm{C} \mathrm{min}^{-1}$ for $1 \mathrm{~h}$ under an air atmosphere in order to optimize the carbon content in the structure and transform the residual metallic Ni into the $\mathrm{NiO}$ phase. After the heat treatment, coral-like yolk-shell $\mathrm{NiO} / \mathrm{C}$ composite microspheres (denoted as CYS-NiO/C) were obtained. For comparison, bare $\mathrm{NiO}$ microspheres with a hollow structure (denoted as hollow $\mathrm{NiO}$ ) were also prepared via spray pyrolysis at $700{ }^{\circ} \mathrm{C}$ in an air atmosphere. The spray solution consisted of only nickel nitrate hexahydrate (without PVP and PS nanobeads).

\subsection{Characterization Techniques}

The morphology of the samples was examined using fieldemission scanning electron microscopy (FE-SEM, ULTRA PLUS, ZEISS) and field-emission transmission electron microscopy (FE-TEM, JEOL, JEM-2100F). The phase analysis of the samples was carried out by X-ray diffraction (XRD, D8 Discover with GADDS, Bruker) using $\mathrm{Cu}$ $\mathrm{K}_{\alpha}$ radiation $(\lambda=1.5418 \AA)$. The chemical composition of the samples was investigated by X-ray photoelectron spectroscopy (XPS, Thermo Scientific $K$-Alpha) using a focused monochromatic $\mathrm{Al} K_{\alpha}$ radiation at $12 \mathrm{kV}$ and $20 \mathrm{~mA}$. Raman spectroscopy (Jobin-Yvon LabRam, HR800, excitation source $=514 \mathrm{~nm} \mathrm{He}-\mathrm{Ne}$ laser ) was conducted to confirm the presence of a graphitic structure in the samples. The surface areas of the samples were estimated using the Brunauer-Emmett-Teller (BET) method where $\mathrm{N}_{2}$ was used as the adsorbate gas. Thermogravimetric analysis (TGA) was carried out using a Pyris 1 TG analyzer (Perkin Elmer) over the temperature range of $25-700{ }^{\circ} \mathrm{C}$ at a heating rate of $10{ }^{\circ} \mathrm{C} \min ^{-1}$ under an air atmosphere.

\subsection{Electrochemical Measurements}

The electrochemical performances of the samples as LIB anodes were evaluated using 2032-type coin cells. The prepared $\mathrm{NiO}$ samples were used as the working electrode composed of $70 \mathrm{wt} \%$ active material, $20 \mathrm{wt} \%$ carbon black (Super-P) as the conductive material, and $10 \mathrm{wt} \%$ sodium carboxymethyl cellulose as the binder on a copper foil. The Li metal and microporous polypropylene film were used as the counter electrode and separator, respectively. The electrolyte used was $1 \mathrm{M} \mathrm{LiPF}_{6}$ in a mixture of fluoroethylene carbonate and dimethyl carbonate with a volume ratio of $1: 1$. The cells were assembled in a glove box under an Ar atmosphere. The electrochemical performances of the samples were evaluated using cyclic voltammetry (CV), charge-discharge testing, and electrochemical impedance spectroscopy (EIS). The mass loading of the samples for the test was $1.0 \mathrm{mg} \mathrm{cm}^{-2}$. The $\mathrm{CV}$ measurements of the samples were carried out at a scan rate of $0.1 \mathrm{mV} \mathrm{s}^{-1}$ over the potential range of $0.001-3.0 \mathrm{~V}$. The charge-discharge testing of the samples was carried out at current densities of $0.5-10.0 \mathrm{~A} \mathrm{~g}^{-1}$ within the same potential window of $0.001-3.0 \mathrm{~V}$. The EIS of the samples was carried out over the frequency range of $100 \mathrm{kHz}-0.01 \mathrm{~Hz}$ using a perturbation of $10 \mathrm{mV}$.

\section{Results and Discussion}

\subsection{Synthesis of $\mathrm{Ni} / \mathrm{NiO} / \mathrm{C}$ Microspheres}

In order to elucidate the formation mechanism of the unique coral-like yolk-shell-structured metal oxide/C composites, the effects of both the reaction temperature during the spray pyrolysis and organic polymers as additives on the microsphere morphologies were investigated in detail. The morphologies of the as-prepared microspheres obtained using the solution with Ni salt, PVP, and containing an optimum amount of PS nanobeads at various reaction temperatures are shown in Fig. 1. As the reaction temperature was increased from 300 to $700{ }^{\circ} \mathrm{C}$, the decomposition of the Ni salt, PVP, and the PS nanobeads occurred sequentially. It should be noted that the PS nanobeads decomposed at temperatures higher than $500{ }^{\circ} \mathrm{C}$, generating numerous mesopores inside the composite structure (Fig. 1c). Subsequently, the inner part of the composite contracted thermally in the hot reaction zone (at $600{ }^{\circ} \mathrm{C}$ ) during the spray pyrolysis, which resulted in the formation of a hollow space between the porous yolk and the shell, as shown in Fig. 1d. The formation of the hollow space between the yolk and the shell during the spray pyrolysis process is illustrated in Fig. S2. Therefore, the morphology of the resulting microspheres changed from dense to the desirable coral-like yolk-shell 


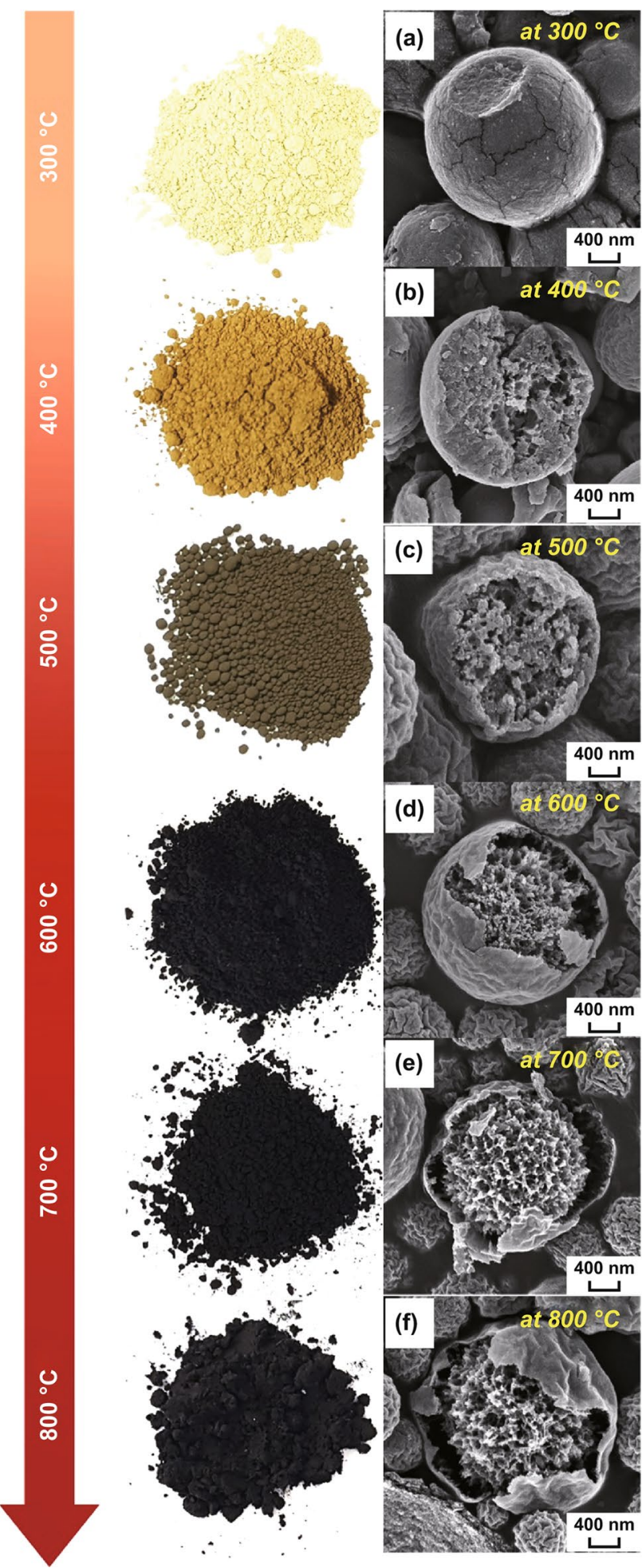

Fig. 1 Morphologies of the as-prepared powders obtained by spray pyrolysis at different temperatures: a $300{ }^{\circ} \mathrm{C}$, b $400{ }^{\circ} \mathrm{C}$, c $500{ }^{\circ} \mathrm{C}$, d $600{ }^{\circ} \mathrm{C}$, e $700{ }^{\circ} \mathrm{C}$, and f $800{ }^{\circ} \mathrm{C}$ structure. The change in the color of the microspheres from yellow to black indicates the carbonization of PVP. Therefore, coral-like yolk-shell-structured microspheres were obtained at temperatures higher than $600{ }^{\circ} \mathrm{C}$.

The interaction between the organic polymer additives (PVP and the PS nanobeads) with the Ni salt significantly affected the microsphere morphology (Fig. 2). The microspheres obtained from the Ni salt-PVP solution (without PS nanobeads) were spherical with a hollow structure and thin walls (Fig. 2a). In the spray pyrolysis process, hollow microspheres are formed by the fast drying of the droplets and the rapid decomposition of metal salts at high temperatures. However, when $10 \mathrm{~g} \mathrm{~L}^{-1}$ PS nanobeads were added to the salt solution as an organic additive, fractured core-shell microspheres with a porous core with well-defined mesopores@ shell with a wrinkled surface were obtained (Fig. 2b). In the drying step during the initial stage of the spray pyrolysis process, PVP in the droplet partially separated from the PS colloidal solution and migrated outward, while the PS nanobeads in the solution moved inward. At the same time, the Ni salt, which had a high affinity toward PVP, was also transferred outward along with PVP. The decomposition of the PS nanobeads resulted in the generation of mesopores in the structure. As the PS nanobead content of the spray solution was increased to $20 \mathrm{~g} \mathrm{~L}^{-1}$, a hollow space was generated in the region between the porous yolk and the shell, as shown in Fig. 2c. This is because of the decomposition of a large amount of PS nanobeads into gaseous products, which resulted in the generation of numerous mesopores inside the carbon composite structure. Subsequently, the inner part of the composite underwent thermal contraction in the hot reaction zone during the spray pyrolysis process, which resulted in the formation of a hollow space between the yolk and the shell. An increase in the PS nanobead content to $40 \mathrm{~g} \mathrm{~L}^{-1}$ resulted in an increase in the hollow space between the porous yolk and the shell, as shown in Fig. 2d. However, a further increase in the PS nanobead content to $80 \mathrm{~g} \mathrm{~L}^{-1}$ resulted in the shrinking of the shell into the vast internal space formed by excessive PS nanobead decomposition owing to the inward force, which resulted in a core-shell structure with a porous core and shell, as shown in Fig. 2e. In addition, an increase in the PS nanobead content (Fig. 2a-e) resulted in the formation of surface wrinkles because of the migration of PVP to the shell part. 

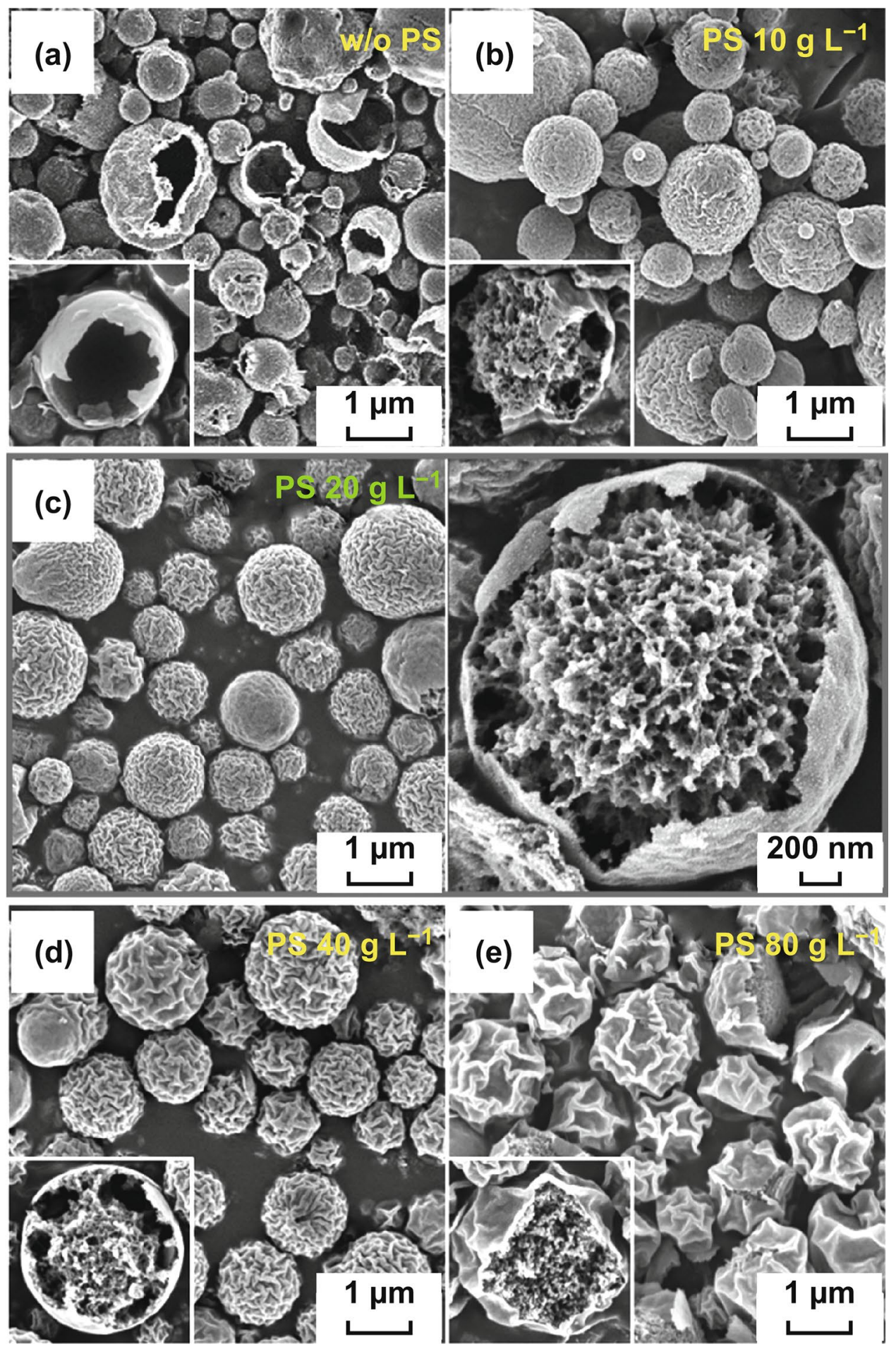

Fig. 2 Morphologies of the as-prepared powders obtained from the solution containing Ni salt, PVP, and a without PS nanobeads, $\mathbf{b}$ with $10 \mathrm{~g}$ $\mathrm{L}^{-1}, \mathbf{c} 20 \mathrm{~g} \mathrm{~L}^{-1}$, d $40 \mathrm{~g} \mathrm{~L}^{-1}$, and e $80 \mathrm{~g} \mathrm{~L}^{-1}$ PS nanobeads 
Moreover, the depth of the surface wrinkles also increased with an increase in the PS nanobead content owing to the thermal contraction of the shell to the interior of the core. In summary, coral-like yolk-shell-structured metal oxide/C composite microspheres can be prepared by controlling the reaction temperature during the spray pyrolysis process and by using organic additives with an optimum ratio of PVP and PS nanobeads.

The morphologies of the CYS-Ni/NiO/C composite microspheres prepared by spray pyrolysis at $700{ }^{\circ} \mathrm{C}$ using the solution with $20 \mathrm{~g} \mathrm{~L}^{-1}$ of PS nanobeads are shown in Fig. 3. The XRD pattern of these microspheres (Fig. 4a) showed the presence of a predominant metallic Ni phase with cubic NiO phases [35]. This indicates that the microspheres were composed of $\mathrm{Ni}, \mathrm{NiO}$, and $\mathrm{C}$ (carbonized by PVP). During the spray pyrolysis, a large number of metallic Ni nanocrystals were formed under a $\mathrm{N}_{2}$ atmosphere through the carbothermal reduction reaction [36]. The CYS-Ni/NiO/C microspheres were spherical with a mean size of $1.3 \mu \mathrm{m}$ and showed wrinkled surfaces owing
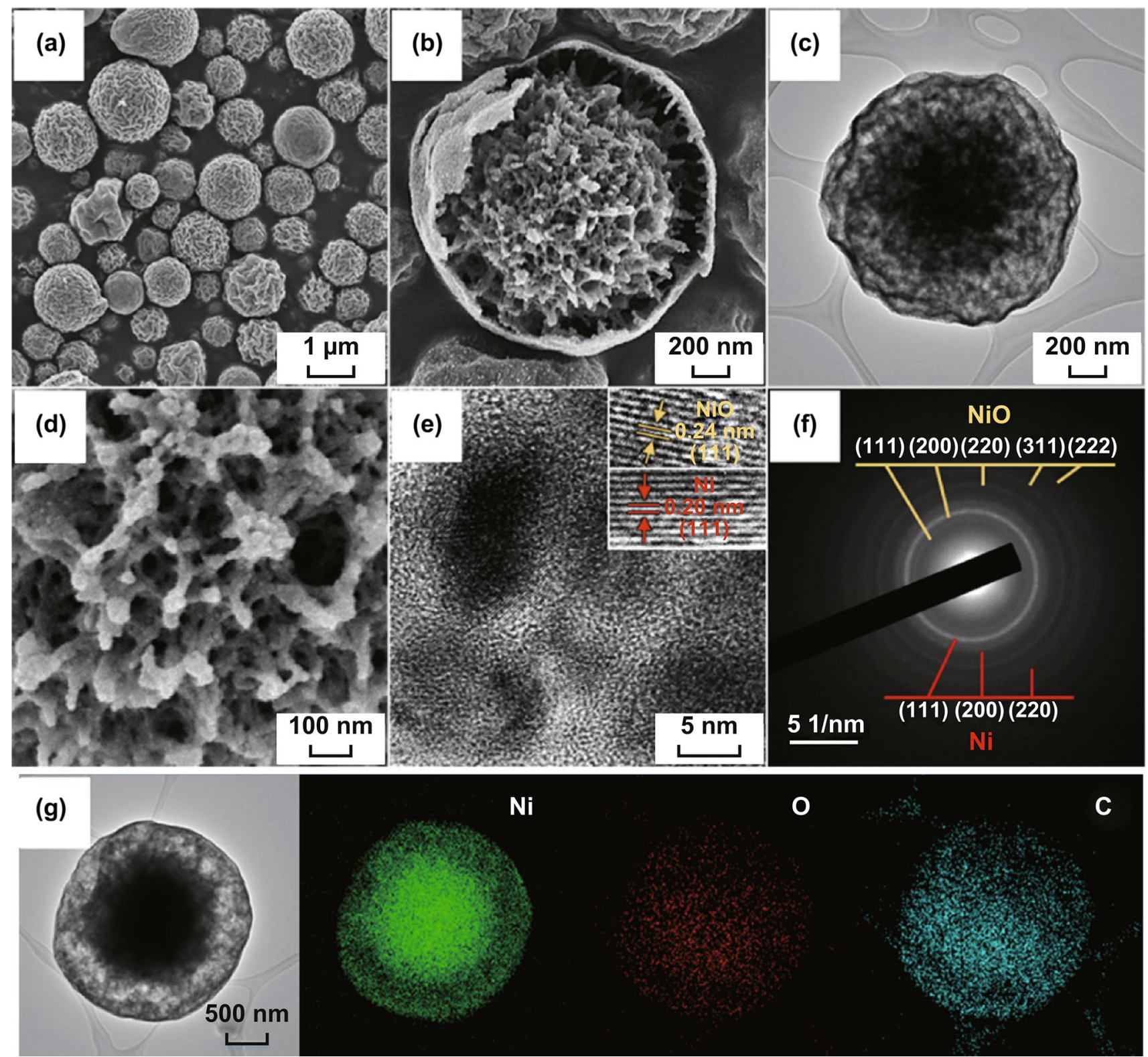

$\mathrm{Ni}$

O

Fig. 3 a, b, d FE-SEM images, c, e HR-TEM images, $\mathbf{f}$ SAED pattern, and $\mathbf{g}$ elemental mapping images of the CYS-Ni/NiO/C microspheres 
to the shrinkage of the shell at the high reaction temperature of $700{ }^{\circ} \mathrm{C}$. The SEM and TEM images in Fig. 3b, c also showed that the microspheres had a distinct corallike yolk-void-shell configuration. The microspheres shown in Fig. 3d showed a coral-like yolk with a definite porous structure, and the mesopores were interconnected with each other. The high-resolution TEM image shown in Fig. 3e reveals that the microspheres consisted of nanocrystals (with a size distribution of 5-10 nm) surrounded by a carbon matrix. The $\mathrm{Ni}$ and $\mathrm{NiO}$ nanocrystals with lattice fringes were separated by gaps of 0.20 and $0.24 \mathrm{~nm}$, which correspond to the (111) plane of the cubic $\mathrm{Ni}$ metal and (111) plane of the cubic NiO, respectively [37]. The selected area electron diffraction (SAED) pattern of the composite microspheres (Fig. 3f) also confirmed the presence of metallic $\mathrm{Ni}$ and $\mathrm{NiO}$ crystals in them. From the elemental mapping images of the microspheres shown in Fig. 3g, it can be observed that Ni was uniformly distributed in the $\mathrm{C}$ matrix. The TGA curve shown in Fig. S3a revealed that the microspheres first showed a slight weight gain and then a sharp weight loss. The weight gain at $240{ }^{\circ} \mathrm{C}$ can be attributed to the conversion of metallic $\mathrm{Ni}$ to $\mathrm{NiO}$. Moreover, the weight loss at $310-400{ }^{\circ} \mathrm{C}$ can be attributed to the combustion of $\mathrm{C}$. The weight loss due to the combustion of a large amount of $\mathrm{C}$ was reduced by continuous Ni oxidation.

\subsection{Synthesis of NiO/C Microspheres}

In order to optimize $\mathrm{C}$ contents and transform metallic $\mathrm{Ni}$ into $\mathrm{NiO}$, the $\mathrm{CYS}-\mathrm{Ni} / \mathrm{NiO} / \mathrm{C}$ microspheres were heattreated at $250{ }^{\circ} \mathrm{C}$, and the resulting CYS-NiO/C composite microspheres without metallic $\mathrm{Ni}$ are shown in Fig. 5. The XRD pattern of the CYS-Ni/NiO/C microspheres (Fig. 4b) confirmed the complete oxidation of metallic $\mathrm{Ni}$ to NiO. The mean crystallite size of $\mathrm{NiO}$ was determined by applying the Scherrer equation to its (200) crystal plane and was found to be $17 \mathrm{~nm}$. The CYS-NiO/C microsphere retained its original coral-like yolk-shell structure despite the heat treatment (Fig. 5a-d). In other words, the microspheres showed the coral-like yolk-void-shell, and the mesopores in the yolk were interconnected even after the heat treatment (Fig. 5d). From the high-resolution TEM image shown in Fig. 5e, it can be observed that $\mathrm{NiO}$ nanocrystals with a size distribution of $10-20 \mathrm{~nm}$ were well distributed in the
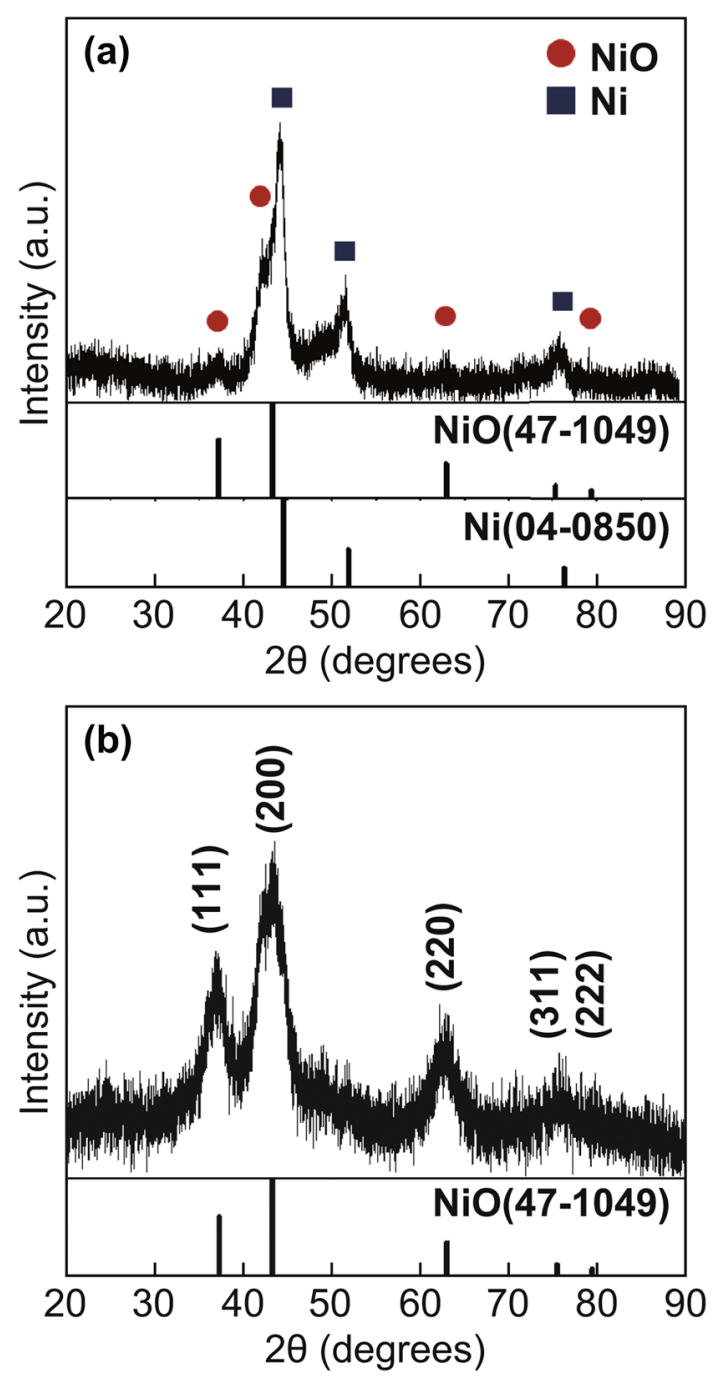

Fig. 4 XRD patterns of the a CYS-Ni/NiO/C and b CYS-NiO/C microspheres

graphitic carbon matrix. The presence of layers with a lattice spacing of $0.34 \mathrm{~nm}$ in the (002) crystal plane confirmed the graphitization of $\mathrm{C}$ [38]. Ni metal acted as a catalyst for the graphitization of $\mathrm{C}$ during the spray pyrolysis process at a relatively low temperature of $700{ }^{\circ} \mathrm{C}[39,40]$. The lattice fringes and SAED pattern (inset of Fig. 5e, f) further confirmed the complete conversion of $\mathrm{Ni}$ into $\mathrm{NiO}$ in the CYS$\mathrm{NiO} / \mathrm{C}$ microsphere. The lattice fringes separated by a gap of $0.21 \mathrm{~nm}$ corresponded to the (200) crystal plane of cubic $\mathrm{NiO}[24,41]$. The elemental mapping image of CYS-NiO/C (Fig. $5 \mathrm{~g}$ ) revealed that the $\mathrm{NiO}$ nanocrystals were uniformly distributed in the $\mathrm{C}$ matrix. The $\mathrm{NiO}$ and $\mathrm{C}$ contents of the CYS-NiO/C microsphere were $82 \%$ and $18 \%$, respectively, as calculated from the TGA results (Fig. S3b). 

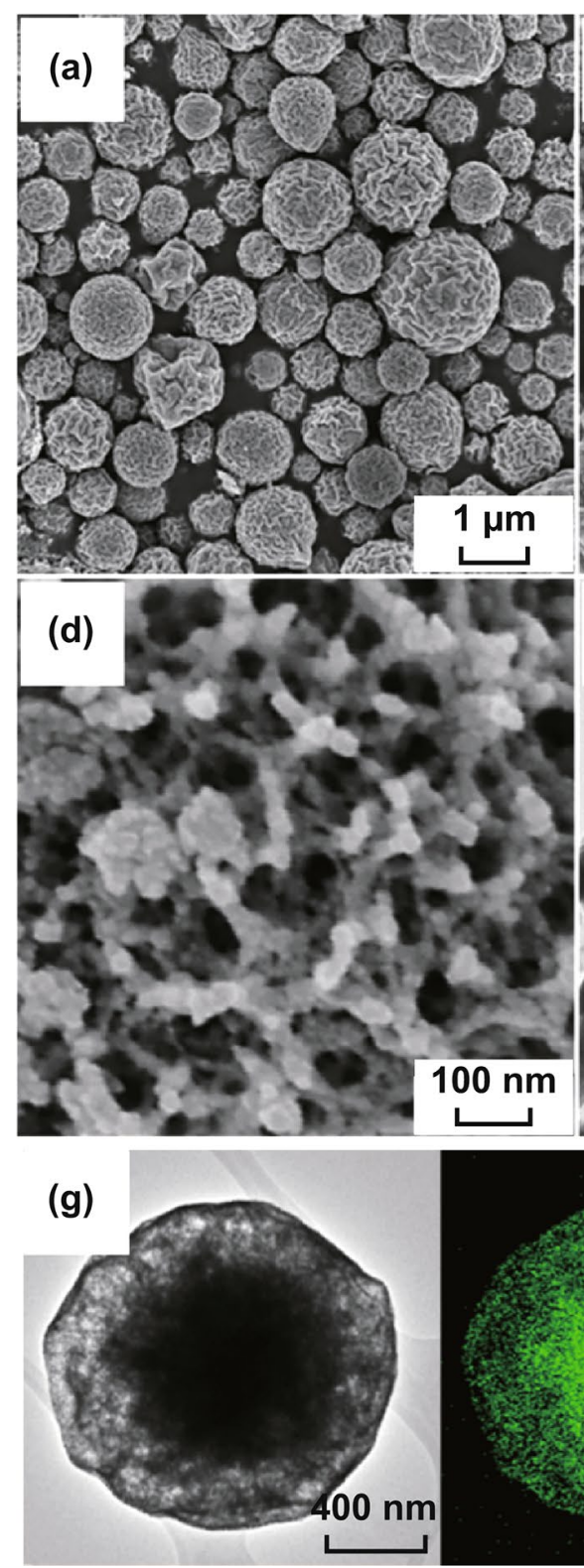
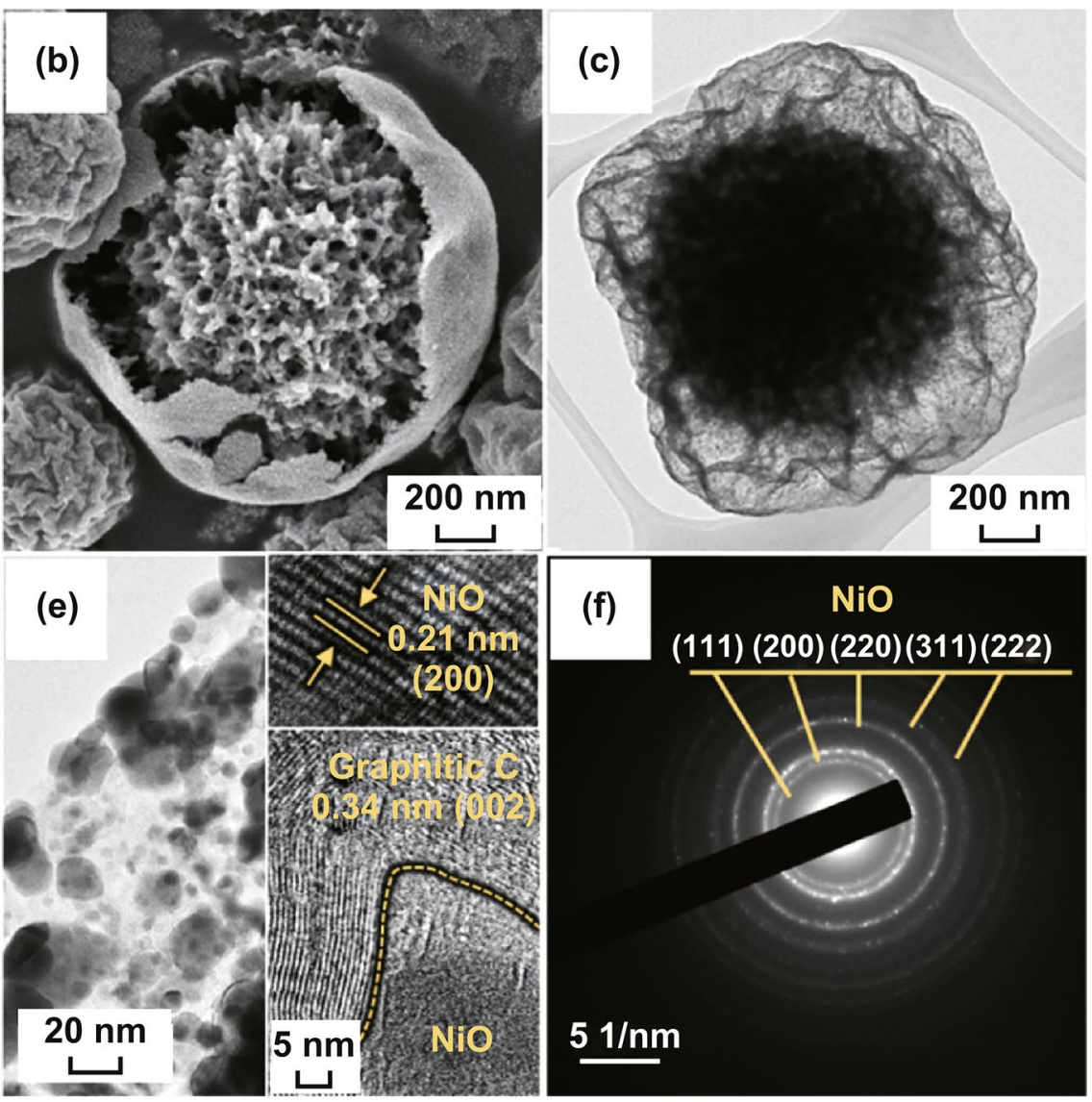

(f)
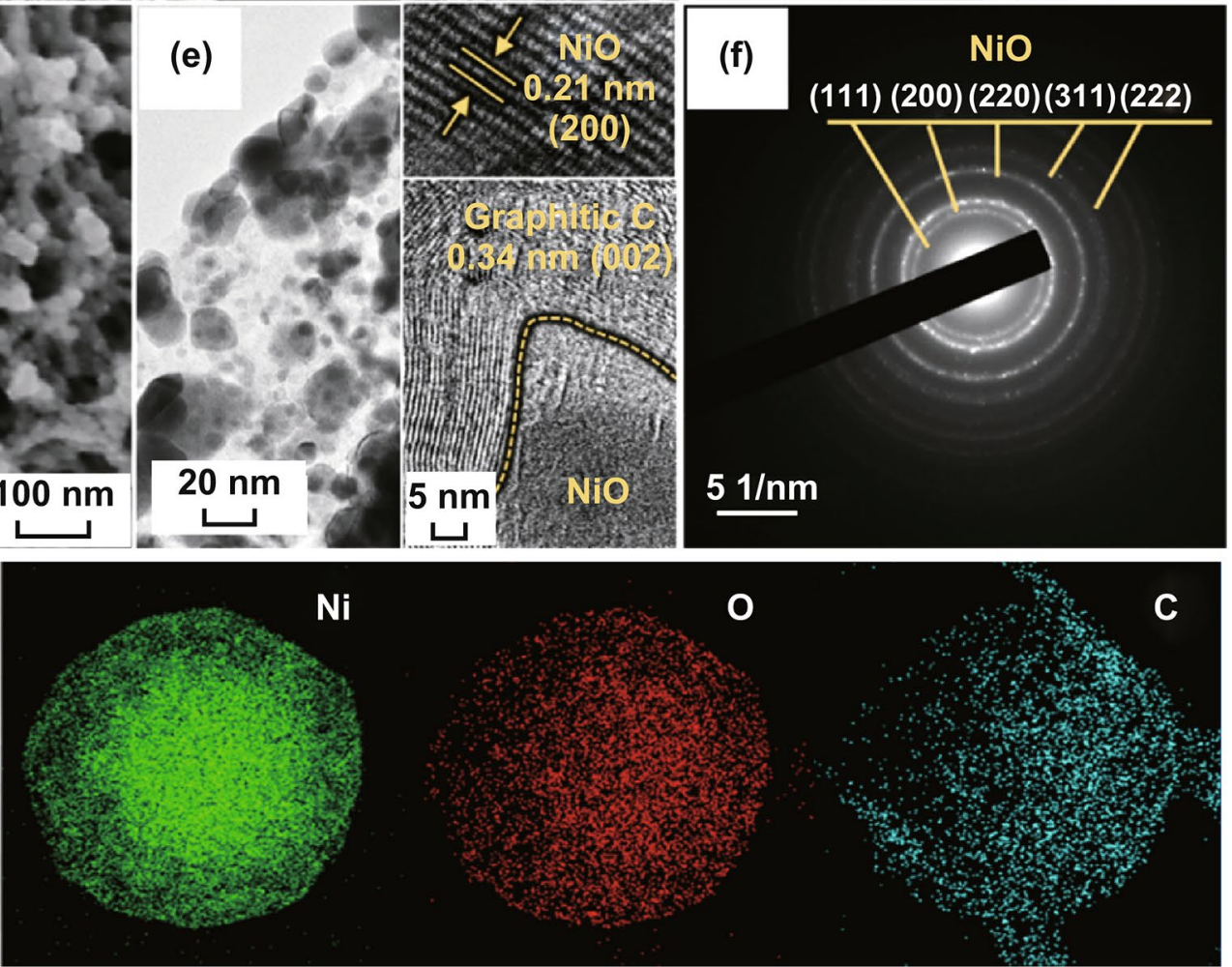

0

C

Fig. 5 a, b, d FE-SEM images, c, e HR-TEM images, f SAED pattern, and $\mathbf{g}$ elemental mapping images of the CYS-NiO/C microspheres

The elemental compositions of the CYS-NiO/C microspheres were analyzed using XPS (Fig. 6a-c). The survey spectrum of the CYS-NiO/C microspheres (in Fig. 6a) showed the presence of $\mathrm{Ni}, \mathrm{O}$, and $\mathrm{C}$ elements, which is consistent with the elemental mapping results (Fig. 5g) [42]. The high-resolution Ni $2 p$ spectrum of the microspheres (Fig. 6b) showed two major Ni $2 p_{3 / 2}$ and Ni $2 p_{1 / 2}$ peaks for $\mathrm{Ni}^{3+}$ and $\mathrm{Ni}^{2+}$, respectively, along with their satellite peaks $[43,44]$. The $\mathrm{Ni}^{3+}$ peak can be attributed to the formation of O-rich nickel oxide owing to the burning of $\mathrm{C}$ during the heat treatment $[43,44]$. However, the amount of O-rich nickel oxide was assumed to be negligible because of the existence of a pure $\mathrm{NiO}$ phase, as confirmed by the XRD results (Fig. $4 b$ ). Figure $6 c$ shows the deconvoluted $\mathrm{C} 1 s$ spectrum of the microspheres. The peaks corresponding to $s p^{2}$-bonded $\mathrm{C}(\mathrm{C}-\mathrm{C}), \mathrm{C}-\mathrm{OH}$, and O-C-O were observed at 284.5, 285.9, and $287.7 \mathrm{eV}$, respectively [45]. The sharp peak corresponding to $s p^{2}$ bonded $\mathrm{C}$ observed in the XPS and Raman spectra of the CYS-NiO/C microspheres (Fig. 6d) further confirmed the 
(a)

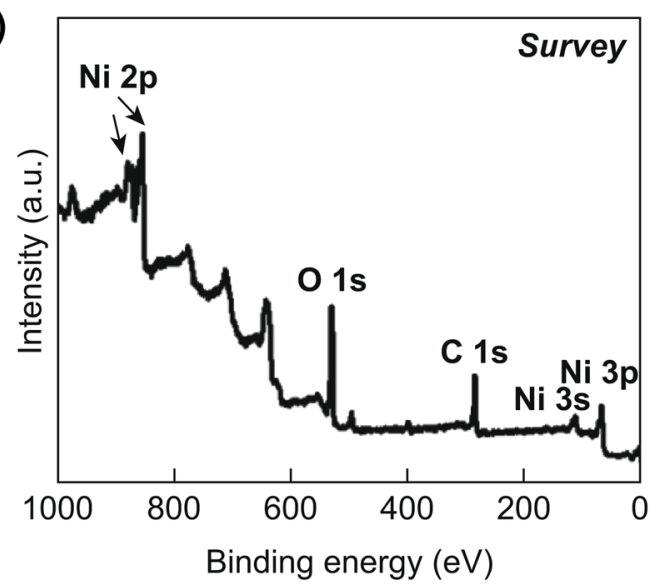

(c)

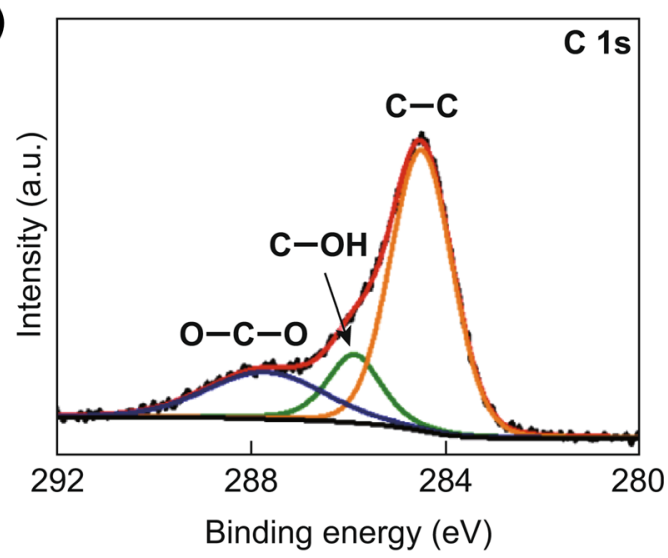

(e)

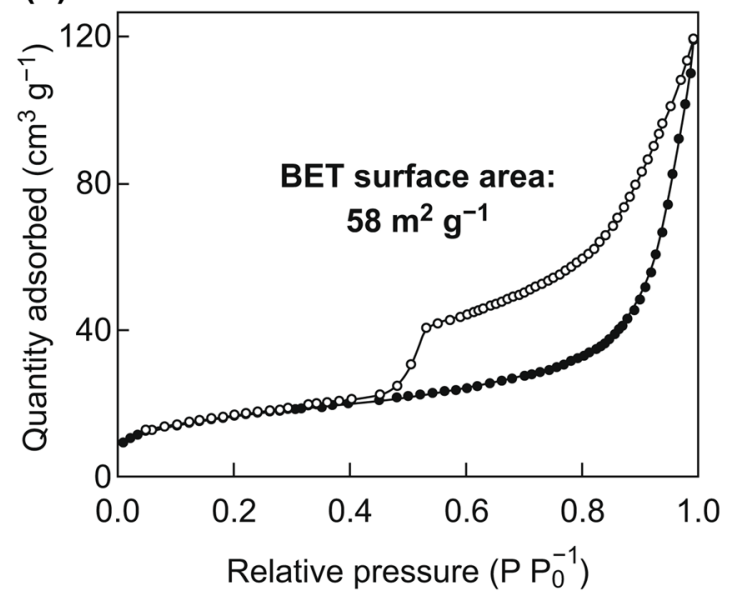

(b)

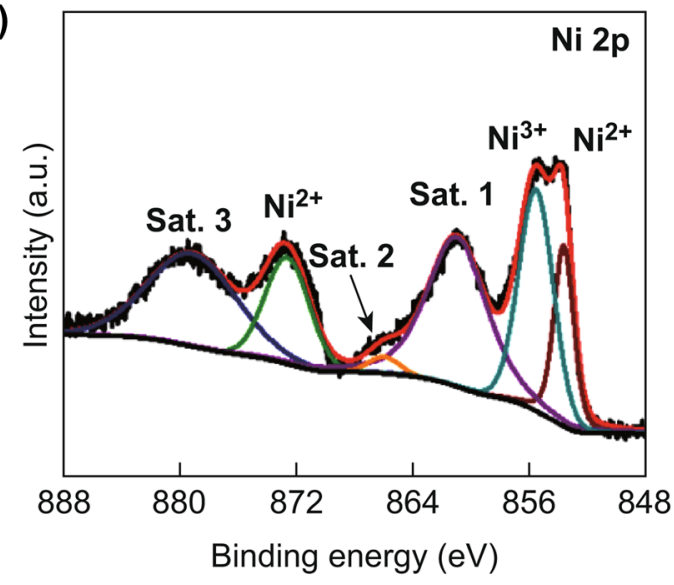

(d)

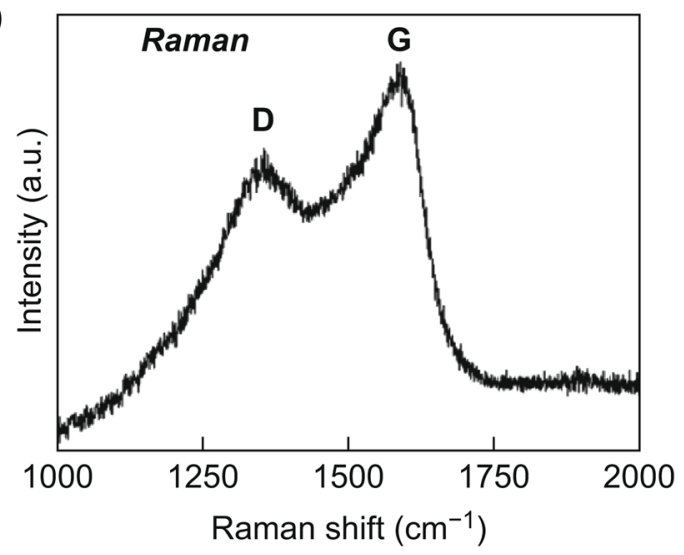

(f)

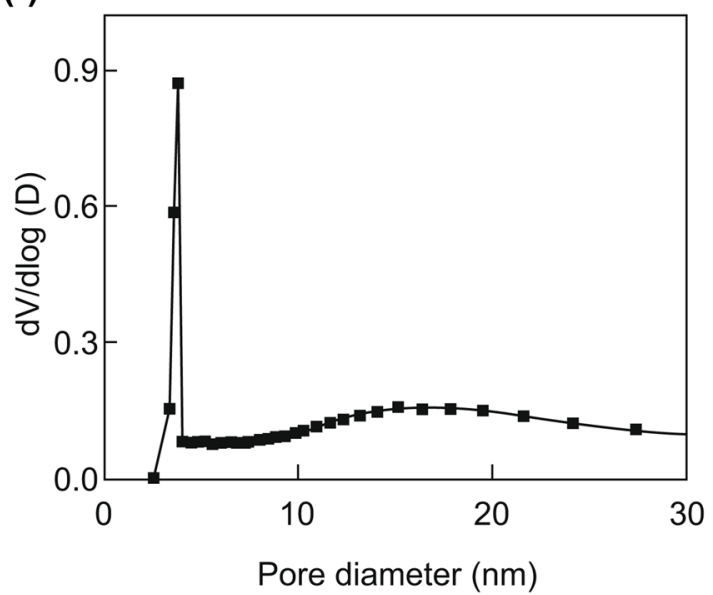

Fig. 6 a Survey XPS, b Ni $2 p$ XPS, c C $1 s$ XPS and d Raman spectra, e $\mathrm{N}_{2}$ adsorption and desorption isotherms, and $\mathbf{f}$ BJH pore size distribution of the CYS-NiO/C microspheres

presence of graphitic carbon in them. The presence of graphitic carbon can be attributed to the graphitization of $\mathrm{C}$, wherein the Ni metal acted as a catalyst. This is consistent with the high-resolution TEM results (Fig. 5e). The $I_{\mathrm{D}} / I_{\mathrm{G}}$ ratio (measure of degree of graphitization) of the CYS-NiO/C microspheres was approximately 0.72 . The $\mathrm{N}_{2}$ adsorption and desorption isotherms (Fig. 6e) and pore distribution curves (Fig. 6f) of the CYS-NiO/C microspheres revealed their porous nature. The isotherms of the CYS-NiO/C microspheres were $\mathrm{H} 3$ type, indicating 
the presence of mesopores within the structure [46]. The BET surface area of the CYS-NiO/C microspheres was $58 \mathrm{~m}^{2} \mathrm{~g}^{-1}$. The CYS-NiO/C microspheres showed two types of mesopores, wherein the mesopores smaller than $10 \mathrm{~nm}$ can be attributed to the spaces uniformly distributed in the $\mathrm{NiO} / \mathrm{C}$ composite, and the relatively larger mesopores can be attributed to the voids formed by the decomposition of PS nanobeads. Additionally, a very sharp peak at $3.8 \mathrm{~nm}$ was observed because of the tensile strength effect evident from the pore distribution curve $[47,48]$. The numerous well-developed mesopores in the structure and $\mathrm{C}$ matrix contributed to the high BET surface area of the CYS-NiO/C microspheres.
The formation mechanism of the CYS-NiO/C composite microspheres can be elucidated as follows: Droplets consisting of uniformly distributed Ni salt, PVP, and PS nanobeads were generated by an ultrasonic nebulizer during the spray pyrolysis process (Scheme 1-(1). PVP bonded with PS in water through the interaction between the hydrophobic PS methylene/methane groups and the positive dipole moment of the pyrrolidone ring amide nitrogen. Additionally, the amide groups of PVP bonded with Ni ions through strong ionic bonds. Therefore, PVP stabilized the PS nanobeads and Ni salt in the droplets generated during the spray pyrolysis process. Upon drying, each droplet (several microns in size) produced one Ni salt-PVP

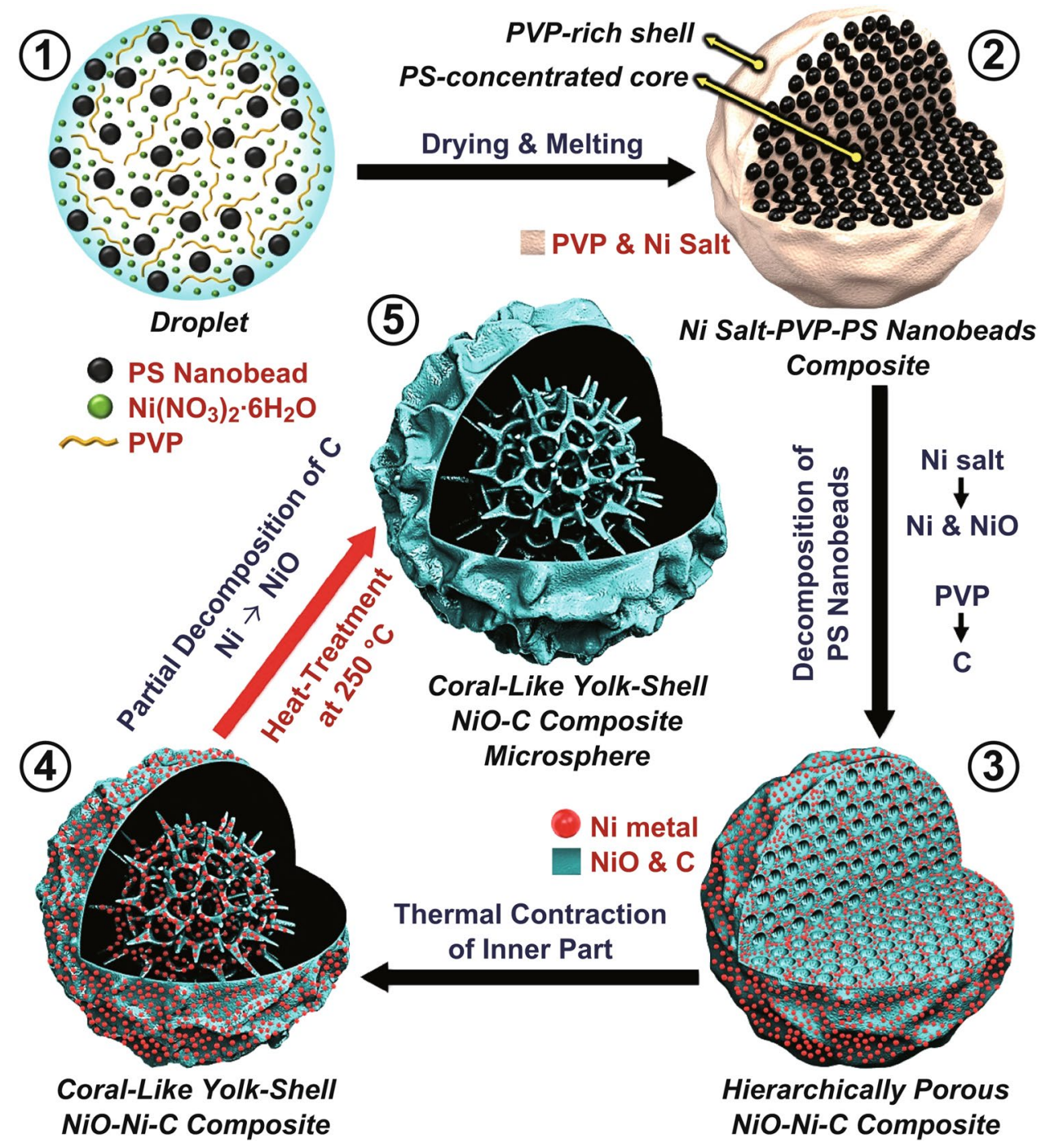

Scheme 1 Formation mechanism of the coral-like yolk-shell-structured NiO/C composite microspheres 
composite microsphere containing numerous 40-nm PS nanobeads. During the spray pyrolysis, PVP melted and partially phase-separated from the PS colloidal solution. It then migrated to the outside of the structure. At the same time, the Ni salt, which had a high affinity toward PVP, also moved outside the structure along with PVP. Here, PS nanobeads were homogeneously dispersed throughout the microspheres except the PVP-rich shell. Hence, a Ni salt-PVP-PS nanobead composite with a PVP-rich shell and PS-concentrated core was formed (Scheme 1-(2). Subsequently, several changes occurred simultaneously, resulting in the formation of a hierarchically porous $\mathrm{NiO}-\mathrm{Ni}-\mathrm{C}$ composite: (1) the decomposition of nickel salt to metallic $\mathrm{Ni}$ and NiO nanocrystals, (2) carbonization of PVP, and (3) formation of mesopores because of the decomposition of PS nanobeads (Scheme 1-(3). The subsequent thermal contraction of the inner part of the structure resulted in the generation of a hollow space between the porous yolk with well-defined voids and the shell in the CYS-Ni/NiO/C microsphere (Scheme 1-(4). Finally, the oxidation of the metallic $\mathrm{Ni}$ and partial decomposition of the $\mathrm{C}$ matrix in the $\mathrm{CYS}-\mathrm{Ni} / \mathrm{NiO} / \mathrm{C}$ microsphere during the post-heat treatment resulted in the formation of a CYS-NiO/C composite microsphere (Scheme 1-5).

\subsection{Evaluation of Li-Ion Storage Performance}

The effects of the morphological features of the CYS-NiO/C and CYS-Ni/NiO/C microspheres on their electrochemical performance as LIB anodes were investigated. Hollow-structured bare $\mathrm{NiO}$ microspheres were directly prepared by spray pyrolysis using a nickel nitrate solution (without both PVP and PS nanobeads) under an air atmosphere for comparison, as shown in Fig. S4. The surface of the droplet was supersaturated by fast drying, which precipitated $\mathrm{NiO}$ crystals on the shell. Subsequently, the Ni salts in the droplet diffused out, resulting in the formation of a $\mathrm{NiO}$ microsphere with a hollow structure. The CV curves for the first five cycles of the CYS-NiO/C microspheres at a scan rate of $0.1 \mathrm{mV} \mathrm{s}^{-1}$ over the potential range of $0.001-3.0 \mathrm{~V}$ (versus $\mathrm{Li}^{+} / \mathrm{Li}$ ) are shown in Fig. 7a. In the first cathodic scan, a reduction peak was observed at approximately $0.64 \mathrm{~V}$ attributing to the initial reduction of $\mathrm{NiO}$ to $\mathrm{Ni}$ accompanied by the formation of amorphous $\mathrm{Li}_{2} \mathrm{O}$ and the decomposition of the electrolyte to form an SEI [24, 49-51]. The relatively weak peak at $0.51 \mathrm{~V}$ can be attributed to structural destruction and was not observed in the subsequent scans [49]. $\mathrm{Li}^{+}$-ion insertion into the graphitic $\mathrm{C}$ matrix was also observed at $0.21 \mathrm{~V}$ [50]. The reduction peaks shifted to higher potentials from the second cycle onwards because of the formation of ultrafine $\mathrm{NiO}$ nanocrystals during cycling [24, 51]. In the anodic scan, from the first cycle onwards, two broad peaks were observed at 1.29 and $2.18 \mathrm{~V}$ corresponding to the dissolution of the organic SEI layer and the subsequent oxidation of the Ni nanocrystals into $\mathrm{NiO}$ along with the decomposition of $\mathrm{Li}_{2} \mathrm{O}$ [24, 49-51]. The excellent reversibility of the discharge-charge process described by the reaction: $\mathrm{NiO}+2 \mathrm{Li}^{+}+2 \mathrm{e}^{-} \leftrightarrow \mathrm{Ni}+\mathrm{Li}_{2} \mathrm{O}$, was ensured by the overlapped $\mathrm{CV}$ profiles in Fig. $7 \mathrm{a}$ after the second cycle $[50,51]$. The $\mathrm{CV}$ curves of the CYS-Ni/NiO/C and hollow NiO microspheres are shown in Fig. S5. The CYS$\mathrm{Ni} / \mathrm{NiO} / \mathrm{C}$ microspheres showed relatively broad $\mathrm{CV}$ peaks with low intensities as compared to the hollow NiO microspheres because of their low-crystalline $\mathrm{NiO}$ composition and high Ni content. An extra reduction peak was observed at $1.1 \mathrm{~V}$ in the first cathodic scan because of the decomposition of the electrolyte and the formation of SEI films [52]. The CV curve of the hollow NiO microsphere exhibited a sharp reduction peak at approximately $0.48 \mathrm{~V}$ owing to the formation of amorphous $\mathrm{Li}_{2} \mathrm{O}$ and the $\mathrm{SEI}$ and the reduction of $\mathrm{NiO}$ into $\mathrm{Ni}$ [24, 49-51]. Among the samples, the CYS$\mathrm{NiO} / \mathrm{C}$ microspheres showed a high-potential reduction peak in the first cathodic scan, indicating that their $\mathrm{Li}^{+}$-ion lithiation/delithiation reactions proceeded readily.

The initial discharge-charge profiles of the CYS-NiO/C, CYS-Ni/NiO/C, and hollow $\mathrm{NiO}$ microspheres at a high current density of $1.0 \mathrm{~A} \mathrm{~g} \mathrm{~g}^{-1}$ are shown in Fig. $7 \mathrm{~b}$. The discharge-charge profiles of the samples were consistent with their $\mathrm{CV}$ results. The discharge curve of the hollow $\mathrm{NiO}$ microspheres featured a clear long plateau at approximately $0.59 \mathrm{~V}$ owing to the presence of highly crystalline $\mathrm{NiO}$ crystals in them [24, 51]. However, the CYS-NiO/C and CYS-Ni/ $\mathrm{NiO} / \mathrm{C}$ microspheres exhibited an unclear plateau because of the presence of $\mathrm{C}$-surrounded $\mathrm{NiO}$ crystals (low crystallinity) in them [24,53]. The initial discharge capacities of the CYS$\mathrm{NiO} / \mathrm{C}, \mathrm{CYS}-\mathrm{Ni} / \mathrm{NiO} / \mathrm{C}$, and hollow $\mathrm{NiO}$ microspheres were 1124,770 , and $1148 \mathrm{mAh} \mathrm{g}^{-1}$, respectively, and their corresponding charge capacities were 778,426 , and $819 \mathrm{mAh} \mathrm{g}^{-1}$, respectively. The theoretical capacity of the CYS-NiO/C microspheres was about $588 \mathrm{mAh} \mathrm{g}^{-1}$, as calculated using the theoretical specific capacities of $\mathrm{NiO}\left(718 \mathrm{mAh} \mathrm{g}^{-1}\right)$ and $\mathrm{C}$ 
(a)

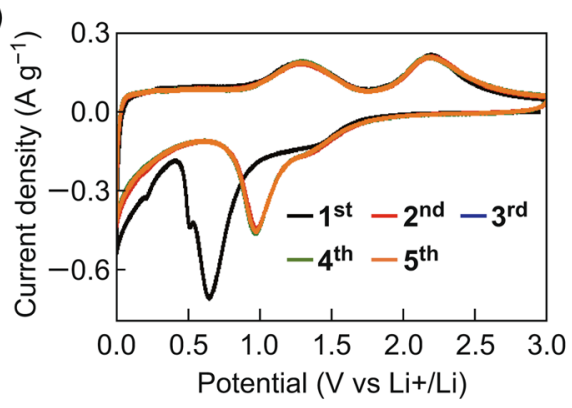

(b)

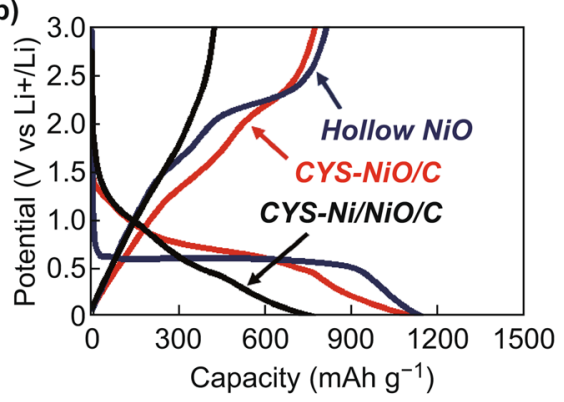

(c)

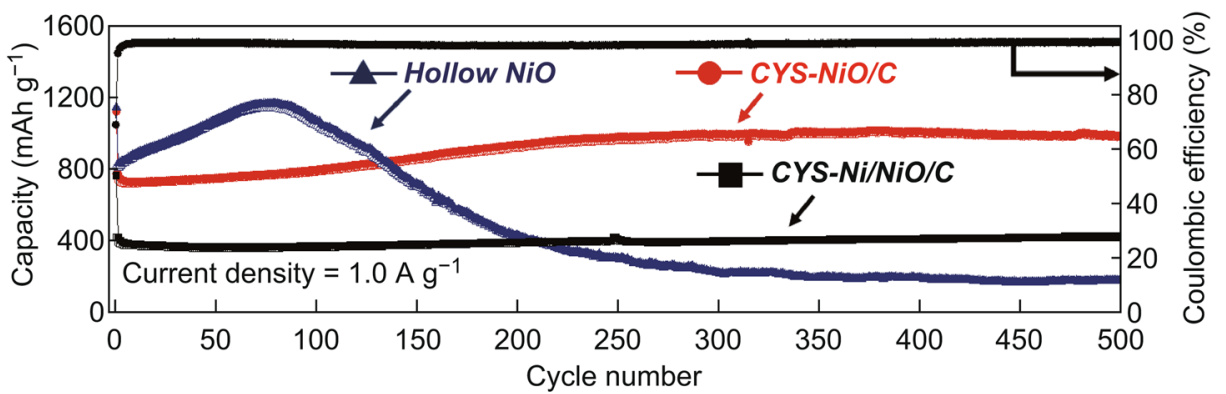

(d)

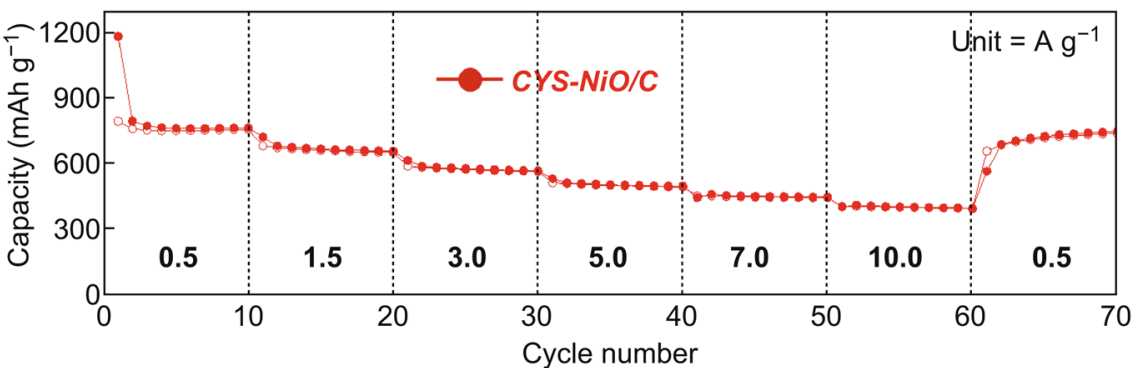

(e)

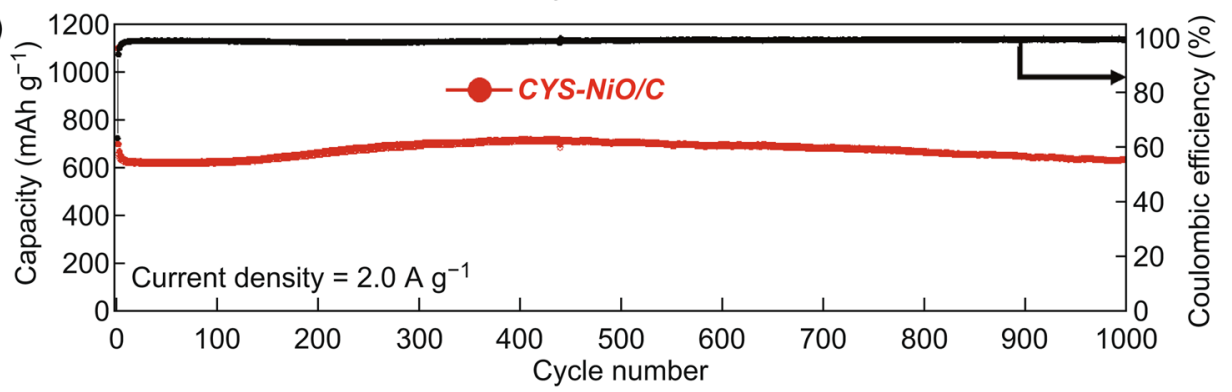

Fig. 7 Electrochemical properties of the CYS-NiO/C, CYS-Ni/NiO/C, and hollow NiO microspheres for lithium-ion storage: a CV curves of the CYS-NiO/C microspheres, $\mathbf{b} 1$ st charge/discharge curves at the current density of $1.0 \mathrm{~A} \mathrm{~g}^{-1}$, $\mathbf{c}$ cycling performance at the current density of $1.0 \mathrm{~A} \mathrm{~g}^{-1}, \mathbf{d}$ rate performance of the CYS-NiO/C microspheres, and e long-term cycling performance of the CYS-NiO/C microspheres at the current density of $2.0 \mathrm{~A} \mathrm{~g}^{-1}$

(372 $\mathrm{mAh} \mathrm{g}^{-1}$ ). The high capacity of the CYS-NiO/C microspheres can be attributed to the partial reversible formation and decomposition of the gel-like SEI film on the surface of the electrode and their pseudo-capacitance [54].The initial Coulombic efficiencies (CE) of the CYS-NiO/C, CYS-Ni/ $\mathrm{NiO} / \mathrm{C}$, and hollow $\mathrm{NiO}$ microspheres were found to be $69 \%$, $55 \%$, and $71 \%$, respectively. The CYS-Ni/NiO/C microspheres showed the lowest CE among the samples because of their high $\mathrm{C}$ content with a high initial irreversible capacity loss [24, 30]. Although the CYS-NiO/C microspheres also had a $\mathrm{C}$ content of $18 \mathrm{wt} \%$, their $\mathrm{CE}$ was comparable to that of the $\mathrm{C}$-free $\mathrm{NiO}$ hollow microspheres. The high structural stability of the CYS-NiO/C microspheres in the first discharge and charge cycles resulted in a high initial CE.

The cycling performances of the samples at the current density of $1.0 \mathrm{~A} \mathrm{~g}^{-1}$ are shown in Fig. 7c. The hollow $\mathrm{NiO}$ 
microspheres showed a gradual increase in the capacity up to 80 cycles. The initial increase in the capacity was due to their pulverization with large $\mathrm{NiO}$ crystals, which resulted in the generation of a fresh metal surface in every cathodic process and the formation of a continuous reversible SEI layer $[46,54,55]$. However, the microspheres showed a drastic decrease in the capacity to $312 \mathrm{mAh} \mathrm{g}^{-1}$ after 250 cycles because of the collapse of their structure by large volume changes during the repeated cycles. In contrast, both the CYS-NiO/C and CYS-Ni/NiO/C microspheres exhibited excellent cycling performances even at the high current density of $1.0 \mathrm{~A} \mathrm{~g}^{-1}$. The CYS-NiO/C microspheres showed a higher specific capacity than that of the CYS-Ni/ $\mathrm{NiO} / \mathrm{C}$ microspheres. This is because the CYS-Ni/NiO/C microspheres are composed of metallic $\mathrm{Ni}$ with inactivity for the LIB reaction and a relatively larger amount of $\mathrm{C}$ content with a low discharge capacity in the structure [52, 53, 56]. The CYS-NiO/C, CYS-Ni/NiO/C, and hollow NiO microspheres delivered reversible specific discharge capacities of 991, 430, and $191 \mathrm{mAh} \mathrm{g}^{-1}$ after 500 cycles, respectively. The CYS-NiO/C microspheres maintained a steady $\mathrm{CE}$ of more than $99.3 \%$. Because of the $\mathrm{C}$-surrounded $\mathrm{NiO}$ crystals, interconnected mesopores in the core, and hollow space between the yolk and the shell, the CYS-NiO/C microspheres effectively accommodated the volume expansion induced by the repeated lithiation/delithiation of $\mathrm{Li}^{+}$ions and showed high cycling stability. Moreover, the fast $\mathrm{Li}^{+}$ ion and electron diffusion in these microspheres resulted in a superior rate performance, as shown in Fig. 7d. The final discharge capacities of the CYS-NiO/C microspheres at the current densities of $0.5,1.5,3.0,5.0,7.0$, and $10.0 \mathrm{~A} \mathrm{~g}^{-1}$ were $753,648,560,490,440$, and $389 \mathrm{mAh} \mathrm{g}^{-1}$, respectively. The coral-like yolk with numerous interconnected mesopores provided easy electrolyte accessibility to the electrode, thus providing a short diffusion length for $\mathrm{Li}^{+}$ ions, which resulted in an excellent rate performance. When the current density was reduced to $0.5 \mathrm{~A} \mathrm{~g}^{-1}$ again, the discharge capacity of the CYS-NiO/C microspheres recovered well to $737 \mathrm{mAh} \mathrm{g}^{-1}$, indicating that their $\mathrm{Li}^{+}$-ion storage performance was not degraded even at high current densities. Since the capacity of the hollow NiO microspheres increased gradually up to 80 cycles (Fig. S6), they showed a higher capacity than the CYS-NiO/C microspheres at the same current density. This can be attributed to the pulverization of the hollow $\mathrm{NiO}$ microspheres with large $\mathrm{NiO}$ crystals, which resulted in the generation of a fresh metal surface in every cathodic process and the formation of a reversible SEI layer continuously up to 80 cycles.

The long-term cycling performance and CE of the CYS$\mathrm{NiO} / \mathrm{C}$ microspheres at the high current density of $2.0 \mathrm{~A} \mathrm{~g}^{-1}$ are shown in Fig. 7e. The discharge capacities at the 2nd and 1000th cycles were 699 and $635 \mathrm{mAh} \mathrm{g}^{-1}$, respectively, and the capacity retention calculated from the second cycle was $91 \%$. The CE of the CYS-NiO/C microspheres reached $99.1 \%$ after the 15 th cycle and remained constant during the subsequent cycles. The $\mathrm{CYS}-\mathrm{NiO} / \mathrm{C}$ microspheres showed the best reversible capacities at high current densities and long-term cycling performance as compared to the other $\mathrm{NiO}$ materials and their carbon hybrids with various morphologies reported previously (Table $\mathrm{S} 1$ ). This can be attributed to the synergetic effect of the coral-like yolk-shell structure with well-defined interconnected mesopores and conductive carbon in these microspheres.

EIS was carried out to investigate the $\mathrm{Li}^{+}$-ion storage kinetics of the CYS-NiO/C, CYS-Ni/NiO/C, and hollow $\mathrm{NiO}$ microspheres. The Nyquist plots of the samples before cycling and after the 200th cycle were obtained via deconvolution using a Randle-type equivalent circuit model, as shown in Fig. S7. The medium-frequency semicircles in the Nyquist plots correspond to the charge-transfer resistance $\left(R_{\mathrm{ct}}\right)$ between the active material and the electrolyte, while the low-frequency region corresponds to the diffusion of $\mathrm{Li}^{+}$ions within the electrodes [57-59]. The $R_{\mathrm{ct}}$ values of the CYS-NiO/C, CYS-Ni/NiO/C, and hollow NiO microspheres before cycling were 314,418 , and $374 \Omega$, respectively, as shown in Fig. 8a. Although the CYS-Ni/NiO/C microspheres consisted of a large amount of $\mathrm{C}$, the presence of amorphous $\mathrm{C}$ contributed to the highest $R_{\mathrm{ct}}$ value. However, the $R_{\mathrm{ct}}$ values of the microspheres decreased abruptly after the 1 st cycle because of the formation of ultrafine $\mathrm{NiO}$ nanocrystals, as shown in Fig. $8 \mathrm{~b}$. The $R_{\mathrm{ct}}$ values of the CYS-NiO/C, CYS-Ni/NiO/C, and hollow $\mathrm{NiO}$ microspheres after the 1 st cycle were 15,22 , and $25 \Omega$, respectively. After 200 cycles, both the CYS-NiO/C and CYS-Ni/NiO/C microspheres with the coral-like yolk-shell structure showed low $R_{\mathrm{ct}}$ values of 18 and $19 \Omega$, respectively. This suggests that these microspheres showed high structural stability during the repeated $\mathrm{Li}^{+}$-ion lithiation/ delithiation processes, as shown in Fig. 8c. The presence of $\mathrm{C}$-surrounded $\mathrm{NiO}$ crystals, interconnected mesopores in the core, and hollow space between the yolk and shell improved the structural stability of the samples. In addition, 
(a)

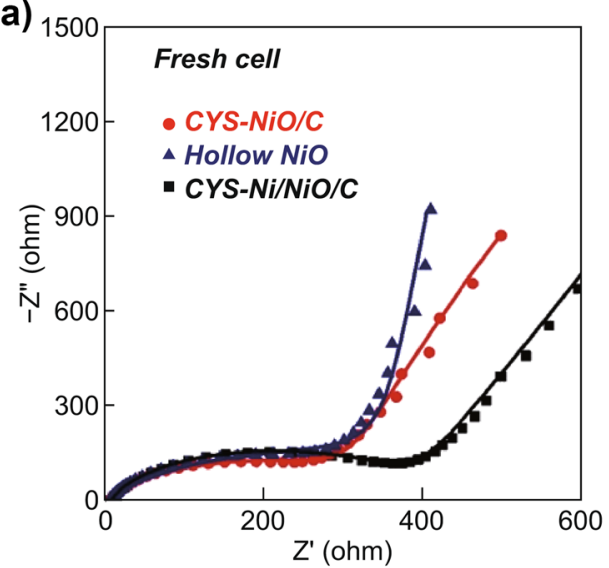

(c)

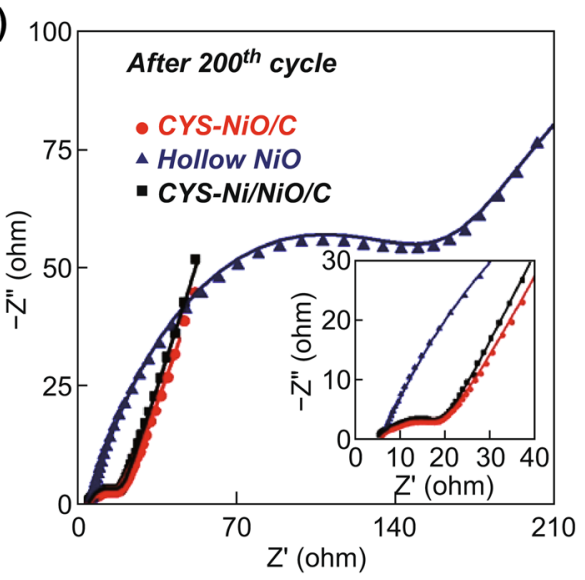

(b)

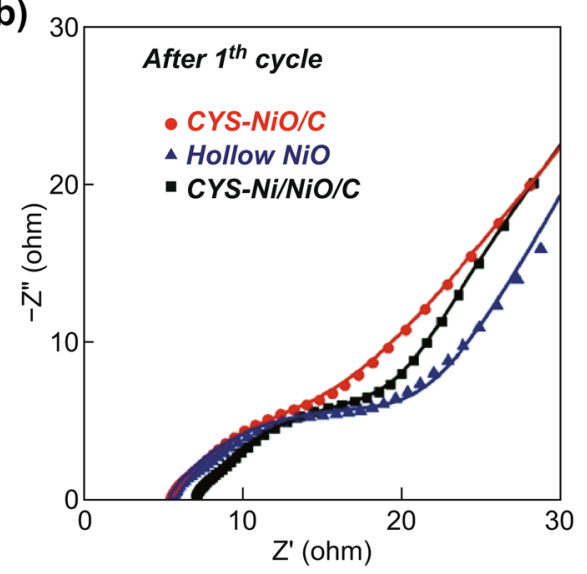

(d)

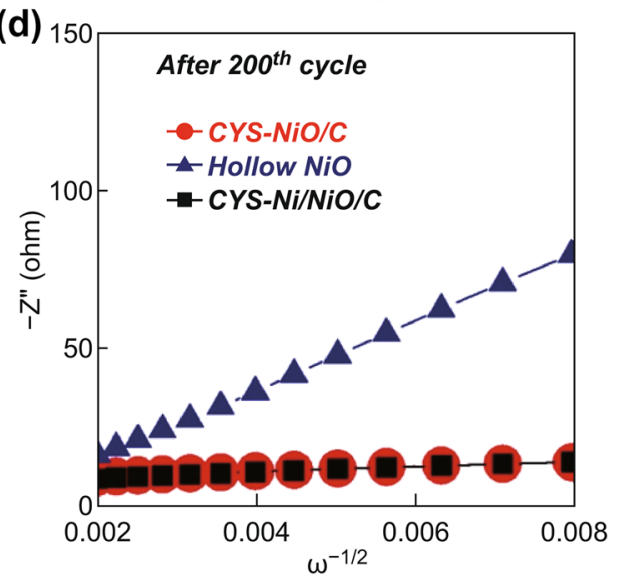

Fig. 8 a-c Nyquist impedance plots (lines represent fitting data) and $\mathbf{d}$ relationships between the real part of the impedance $\left(Z_{\mathrm{re}}\right)$ and $\omega^{-1 / 2}$ of the CYS-NiO/C, CYS-Ni/NiO/C, and hollow NiO microspheres: a before cycling, $\mathbf{b}$ after the 1 st cycle, $\mathbf{c}, \mathbf{d}$ after the 200 th cycle

the easy electrolyte accessibility of the electrode and the short diffusion length of $\mathrm{Li}^{+}$ions lowered the charge-transfer resistance of the microspheres. However, the structural destruction of the hollow $\mathrm{NiO}$ microspheres during cycling significantly increased their $R_{\mathrm{ct}}$ value to $223 \Omega$. Figure $8 \mathrm{~d}$ shows the relationship between the $Z_{\text {re }}$ and $\omega^{-1 / 2}$ [of the samples $\omega$ is the angular frequency in the low-frequency region $(\omega=2 \pi f)]$ in the low-frequency region after 200 cycles. The low slope of the fitted curve of the electrodes at low frequencies indicates their good $\mathrm{Li}^{+}$-ion kinetics in the electrode materials. Both the CYS-NiO/C and CYS-Ni/ $\mathrm{NiO} / \mathrm{C}$ microspheres showed lower gradients than that of the hollow $\mathrm{NiO}$ microspheres. This result suggests that the CYS-NiO/C and CYS-Ni/NiO/C microspheres showed better diffusion of the $\mathrm{Li}^{+}$-ion diffusion than the hollow $\mathrm{NiO}$ microspheres. The interconnected mesopores in the core and the hollow space between the yolk and shell of the coral-like yolk-shell structures allowed the easy electrolyte accessibility to the electrode and shortened the diffusion length of $\mathrm{Li}^{+}$ions. In order to confirm this, the morphologies of the samples were examined after 200 cycles. Figure 9a clearly shows the cycle-induced structural collapse of the hollow NiO microspheres. However, the CYS-NiO/C and CYS-Ni/NiO/C microspheres showed excellent structural stability for repeated $\mathrm{Li}^{+}$-ion insertion and desertion over 200 cycles (Fig. 9b and d, respectively). The CYS$\mathrm{NiO} / \mathrm{C}$ microspheres maintained their coral-like yolk-shell structure (with the shell composed of $\mathrm{NiO}$ and C) (TEM image shown in Fig. 9c). The unique microspheres exhibited long-term cycling and high rate performances during repeated $\mathrm{Li}^{+}$-ion insertion and desertion because of the synergetic effect of the coral-like yolk-shell structure with well-defined interconnected mesopores and conductive carbon. 

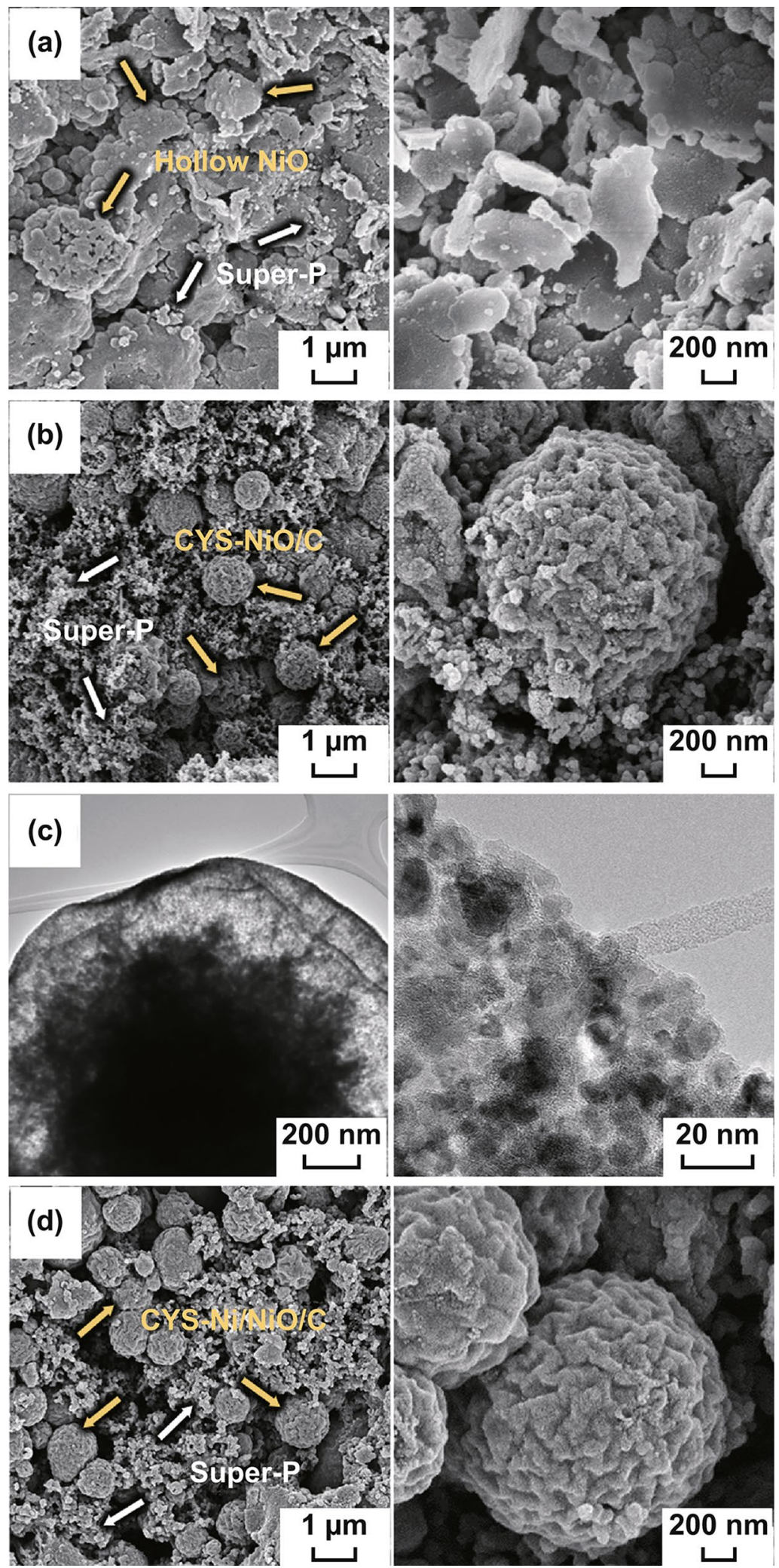

Fig. 9 Morphologies of a hollow NiO, b, c CYS-NiO/C, and $\mathbf{d} \mathrm{CYS}-\mathrm{Ni} / \mathrm{NiO} / \mathrm{C}$ microspheres after the 200th cycles: a, b, $\mathbf{d}$ FE-SEM images and c TEM images 


\section{Conclusions}

In this study, coral-like yolk-shell-structured metal oxide/ carbon composite microspheres were prepared using spray pyrolysis for the first time. During the spray pyrolysis, PVP in the droplet partially phase-separated from the PS colloidal solution and migrated outward, and interconnected mesopores were formed by the decomposition of PS. The subsequent thermal contraction of the inner part of the composites at high reaction temperatures during the spray pyrolysis resulted in the formation of unique CYS-NiO/C microspheres. The CYS-NiO/C microspheres exhibited excellent electrochemical properties for $\mathrm{Li}^{+}$-ion storage because of their high structural stability, shortened $\mathrm{Li}^{+}$-ion diffusion paths, high electrical conductivity, and easy penetration of the electrolyte into the yolk during the repeated $\mathrm{Li}^{+}$lithiation/delithiation processes. We believe that this novel strategy can be used for designing and synthesizing unique corallike yolk-shell-structured metal oxide/carbon composites for a wide range of applications such as catalysis, gas sensors, and hydrogen evolution reactions, and energy storage.

Acknowledgements This work was supported by the National Research Foundation of Korea (NRF) Grant funded by the Korea government (MSIP) (NRF-2018R1A4A1024691, NRF2017M1A2A2087577, and NRF-2018R1D1A3B07042514).

Open Access This article is distributed under the terms of the Creative Commons Attribution 4.0 International License (http:// creativecommons.org/licenses/by/4.0/), which permits unrestricted use, distribution, and reproduction in any medium, provided you give appropriate credit to the original author(s) and the source, provide a link to the Creative Commons license, and indicate if changes were made.

Electronic supplementary material The online version of this article (https://doi.org/10.1007/s40820-018-0234-0) contains supplementary material, which is available to authorized users.

\section{References}

1. M. Mao, F. Yan, C. Cui, J. Ma, M. Zhang, T. Wang, C. Wang, Pipe-wire $\mathrm{TiO}_{2}-\mathrm{Sn} @$ carbon nanofibers paper anodes for lithium and sodium ion batteries. Nano Lett. 17(6), 3830-3836 (2017). https://doi.org/10.1021/acs.nanol ett. $7 \mathrm{~b} 01152$

2. L. Shen, S. Chen, J. Maier, Y. Yu, Carbon-coated $\mathrm{Li}_{3} \mathrm{VO}_{4}$ spheres as constituents of an advanced anode material for high-rate long-life lithium-ion batteries. Adv. Mater.
29(33), 1701571-1701577 (2017). https://doi.org/10.1002/ adma.201701571

3. J.S. Cho, Y.J. Hong, Y.C. Kang, Design and synthesis of bubble-nanorod-structured $\mathrm{Fe}_{2} \mathrm{O}_{3}$ carbon nanofibers as advanced anode material for Li-ion batteries. ACS Nano 9(4), 40264035 (2015). https://doi.org/10.1021/acsnano.5b00088

4. W. Li, L. Zeng, Y. Wu, Y. Yu, Nanostructured electrode materials for lithium-ion and sodium ion batteries via electrospinning. Sci. China Mater. 59(4), 287-321 (2016). https://doi. org/10.1007/s40843-016-5039-6

5. C. Tang, Y. Liu, C. Xu, J. Zhu, X. Wei, L. Zhou, L. He, W. Yang, L. Mai, Ultrafine nickel nanoparticle-enabled $\mathrm{SiO}_{2}$ hierarchical hollow spheres for high-performance lithium storage. Adv. Funct. Mater. 28(3), 1704561 (2018). https:// doi.org/10.1002/adfm.201704561

6. H. Liu, D. Su, G. Wang, S. Qiao, An ordered mesoporous $\mathrm{WS}_{2}$ anode material with superior electrochemical performance for lithium ion batteries. J. Mater. Chem. 22(34), 17437-17440 (2012). https://doi.org/10.1039/C2JM33992G

7. X. Li, M. Gu, S. Hu, R. Kennard, P. Yan, X. Chen, C. Wang, M.J. Sailor, J.G. Zhang, J. Liu, Mesoporous silicon sponge as an anti-pulverization structure for high-performance lithiumion battery anodes. Nat. Commun. 5, 4105 (2014). https://doi. org/10.1038/ncomms5105

8. J.W. Choi, D. Aurbach, Promise and reality of post-lithiumion batteries with high energy densities. Nat. Rev. Mater. 1(4), 16013 (2016). https://doi.org/10.1038/natrevmats.2016.13

9. R. Dai, Y. Wang, P. Da, H. Wu, M. Xu, G. Zheng, Indirect growth of mesoporous $\mathrm{Bi} @ \mathrm{C}$ core-shell nanowires for enhanced lithium-ion storage. Nanoscale 6(21), 13236-13241 (2014). https://doi.org/10.1039/C4NR04378B

10. Q. An, F. Lv, Q. Liu, C. Han, K. Zhao, J. Sheng, Q. Wei, M. Yan, L. Mai, Amorphous vanadium oxide matrixes supporting hierarchical porous $\mathrm{Fe}_{3} \mathrm{O}_{4}$ /graphene nanowires as a high-rate lithium storage anode. Nano Lett. 14(11), 6250-6256 (2014). https://doi.org/10.1021/nl5025694

11. C. Yang, Y. Jiang, X. Liu, X. Zhong, Y. Yu, Germanium encapsulated in sulfur and nitrogen co-doped 3D porous carbon as an ultra-long-cycle life anode for lithium ion batteries. J. Mater. Chem. A 4(48), 18711-18716 (2016). https://doi. org/10.1039/C6TA08681K

12. H. Li, M. Liang, W. Sun, Y. Wang, Bimetal-organic framework: one-step homogenous formation and its derived mesoporous ternary metal oxide nanorod for high-capacity, high-rate, and long-cycle-life lithium storage. Adv. Funct. Mater. 26(7), 1098-1103 (2016). https://doi.org/10.1002/ adfm.201504312

13. Z. Chen, M. Zhou, Y. Cao, X. Ai, H. Yang, J. Liu, In situ generation of few-layer graphene coatings on $\mathrm{SnO}_{2}-\mathrm{SiC}$ core-shell nanoparticles for high-performance lithium-ion storage. Adv. Energy Mater. 2(1), 95-102 (2012). https://doi.org/10.1002/ aenm.201100464

14. H. Liu, G. Wang, J. Liu, S. Qiao, H. Ahn, Highly ordered mesoporous $\mathrm{NiO}$ anode material for lithium ion batteries with an excellent electrochemical performance. J. Mater. Chem. 
21(9), 3046-3052 (2011). https://doi.org/10.1039/C0JM0 $3132 \mathrm{~A}$

15. Y. Zhao, X. Li, B. Yan, D. Xiong, D. Li, S. Lawes, X. Sun, Recent developments and understanding of novel mixed transition-metal oxides as anodes in lithium ion batteries. Adv. Energy Mater. 6(8), 1502175 (2016). https://doi.org/10.1002/ aenm. 201502175

16. T. Li, X. Li, Z. Wang, H. Guo, Y. Li, J. Wang, A new design concept for preparing nickel-foam-supported metal oxide microspheres with superior electrochemical properties. J. Mater. Chem. A 5(26), 13469-13474 (2017). https://doi. org/10.1039/C7TA02789C

17. Z. Cai, L. Xu, M. Yan, C. Han, L. He et al., Manganese oxide/ carbon yolk-shell nanorod anodes for high capacity lithium batteries. Nano Lett. 15(1), 738-744 (2014). https://doi. org/10.1021/nl504427d

18. X. Fan, J. Shao, X. Xiao, X. Wang, S. Li, H. Ge, L. Chen, C. Wang, In situ synthesis of $\mathrm{SnO}_{2}$ nanoparticles encapsulated in micro/mesoporous carbon foam as a high-performance anode material for lithium ion batteries. J. Mater. Chem. A 2(43), 18367-18374 (2014). https://doi.org/10.1039/C4TA04278F

19. Y.L. Wang, J.J. Xu, H. Wu, M. Xu, Z. Peng, G. Zheng, Hierarchical $\mathrm{SnO}_{2}-\mathrm{Fe}_{2} \mathrm{O}_{3}$ heterostructures as lithium-ion battery anodes. J. Mater. Chem. 22(41), 21923-21927 (2012). https ://doi.org/10.1039/C2JM35255A

20. Y. Zhu, S.H. Choi, X. Fan, J. Shin, Z. Ma, M.R. Zachariah, J.W. Choi, C. Wang, Recent progress on spray pyrolysis for high performance electrode materials in lithium and sodium rechargeable batteries. Adv. Energy Mater. 7(7), 1601578 (2017). https://doi.org/10.1002/aenm.201601578

21. L. Zhang, K. Zhao, R. Yu, M. Yan, W. Xu et al., Phosphorus enhanced intermolecular interactions of $\mathrm{SnO}_{2}$ and graphene as an ultrastable lithium battery anode. Small 13(20), 1603973 (2017). https://doi.org/10.1002/smll.201603973

22. T. Wang, Z. Peng, Y. Wang, J. Tang, G. Zheng, MnO nanoparticle@mesoporous carbon composites grown on conducting substrates featuring high-performance lithium-ion battery, supercapacitor and sensor. Sci. Rep. 3, 2693 (2013). https:// doi.org/10.1038/srep02693

23. S.M. Lee, S.H. Choi, Y.C. Kang, Electrochemical properties of tin oxide flake/reduced graphene oxide/carbon composite powders as anode materials for lithium-ion batteries. Chem. Eur. J. 20(46), 15203-15207 (2014). https://doi.org/10.1002/ chem.201404077

24. S.H. Oh, J.S. Park, M.S. Jo, Y.C. Kang, J.S. Cho, Design and synthesis of tube-in-tube structured $\mathrm{NiO}$ nanobelts with superior electrochemical properties for lithium-ion storage. Chem. Eng. J. 347, 889-899 (2018). https://doi.org/10.1016/j. cej.2018.04.156

25. L. Xia, S. Wang, G. Liu, L. Ding, D. Li, H. Wang, S. Qiao, Flexible $\mathrm{SnO}_{2} / \mathrm{N}$-doped carbon nanofiber films as integrated electrodes for lithium-ion batteries with superior rate capacity and long cycle life. Small 12(7), 853-859 (2016). https ://doi.org/10.1002/smll.201503315

26. J. Zhu, Y.K. Sharma, Z. Zeng, X. Zhang, M. Srinivasan, S. Mhaisalkar, H. Zhang, H.H. Hng, Q. Yan, Cobalt oxide nanowall arrays on reduced graphene oxide sheets with controlled phase, grain size, and porosity for Li-ion battery electrodes. J. Phy. Chem. C 115(16), 8400-8406 (2011). https://doi.org/10.1021/jp2002113

27. K. Zeng, X. Li, Z. Wang, H. Guo, J. Wang, T. Li, W. Pan, K. Shih, Cave-embedded porous $\mathrm{Mn}_{2} \mathrm{O}_{3}$ hollow microsphere as anode material for lithium ion batteries. Electrochim. Acta 247, 795-802 (2017). https://doi.org/10.1016/j.elect acta.2017.07.070

28. X. Ahang, R. Zhao, Q. Wu, W. Li, C. Shen, L. Ni, H. Yan, G. Daio, M. Chen, Ultrathin $\mathrm{WS}_{2}$ nanosheets vertically embedded in a hollow mesoporous carbon framework-a tripleshell structure with enhanced lithium storage and electrocatalytic properties. J. Mater. Chem. A 6(39), 19004-19012 (2018). https://doi.org/10.1039/C8TA05584J

29. J.S. Cho, Y.C. Kang, Nanofibers comprising yolk-shell Sn@ void@ $\mathrm{SnO} / \mathrm{SnO}_{2}$ and hollow $\mathrm{SnO} / \mathrm{SnO}_{2}$ and $\mathrm{SnO}_{2}$ nanospheres via the kirkendall diffusion effect and their electrochemical properties. Small 11(36), 4673-4681 (2015). https ://doi.org/10.1002/smll.201500940

30. C. Wu, X. Tong, Y. Ai, D.-S. Liu, P. Yu, J. Wu, Z.M. Wang, A. Review, Enhanced anodes of Li/Na-ion batteries based on yolk-shell structured nanomaterials. Nano-Micro Lett. 10, 40 (2018). https://doi.org/10.1007/s40820-018-0194-4

31. X. Zhang, R. Zhao, Q. Wu, W. Li, C. Shen, L. Ni, H. Yan, G. Diao, M. Chen, Petal-like $\mathrm{MoS}_{2}$ nanosheets space-confined in hollow mesoporous carbon spheres for enhanced lithium storage performance. ACS Nano 11(8), 8429-8436 (2017). https://doi.org/10.1021/acsnano.7b04078

32. H. Zhang, L. Zhou, O. Noonan, D.J. Martin, A.K. Whittaker, C. Yu, Tailoring the void size of iron oxide@ carbon yolkshell structure for optimized lithium storage. Adv. Funct. Mater. 24(27), 4337-4342 (2014). https://doi.org/10.1002/ adfm. 201400178

33. L. Yu, B. Guan, W. Xiao, X.W. Lou, Formation of yolkshelled Ni-Co mixed oxide nanoprisms with enhanced electrochemical performance for hybrid supercapacitors and lithium ion batteries. Adv. Energy Mater. 5(21), 1500981 (2015). https://doi.org/10.1002/aenm.201500981

34. J.H. Kim, Y.C. Kang, Synthesis of uniquely structured yolkshell metal oxide microspheres filled with nitrogen-doped graphitic carbon with excellent Li-ion storage performance. Small 13(39), 1701585 (2017). https://doi.org/10.1002/ smll.201701585

35. W. You, R. Che, Excellent NiO-Ni nanoplate microwave absorber via pinning effect of antiferromagnetic-ferromagnetic interface. ACS Appl. Mater. Interfaces 10(17), 1510415111 (2018). https://doi.org/10.1021/acsami.8b03610

36. B.V. L'vov, Mechanism of carbothermal reduction of iron, cobalt, nickel and copper oxides. Thermochim. Acta 360(2), 109-120 (2000). https://doi.org/10.1016/S0040 $-6031(00) 00540-2$

37. H. Lai, Q. Wu, J. Zhao, L. Shang, H. Li et al., Mesostructured $\mathrm{NiO} / \mathrm{Ni}$ composites for high-performance electrochemical energy storage. Energy Environ. Sci. 9(6), 2053-2060 (2016). https://doi.org/10.1039/C6EE00603E 
38. J.S. Park, S.Y. Jeong, K.M. Jeon, Y.C. Kang, J.S. Cho, Iron diselenide combined with hollow graphitic carbon nanospheres as a high-performance anode material for sodiumion batteries. Chem. Eng. J. 339, 97-107 (2018). https://doi. org/10.1016/j.cej.2018.01.118

39. M. Sevilla, A.B. Fuertes, Catalytic graphitization of templated mesoporous carbons. Carbon 44(3), 468-474 (2006). https:// doi.org/10.1016/j.carbon.2005.08.019

40. J.S. Cho, J.M. Won, J.K. Lee, Y.C. Kang, Design and synthesis of multiroom-structured metal compounds-carbon hybrid microspheres as anode materials for rechargeable batteries. Nano Energy 26, 466-478 (2016). https://doi.org/10.1016/j. nanoen.2016.06.012

41. H. Long, T. Shi, H. Hu, S. Jiang, S. Xi, Z. Tang, Growth of hierarchal mesoporous $\mathrm{NiO}$ nanosheets on carbon cloth as binder-free anodes for high-performance flexible lithium-ion batteries. Sci. Rep. 4, 7413 (2014). https://doi.org/10.1038/ srep07413

42. L. Yu, G. Wan, X. Peng, Z. Dou, X. Li, K. Wang, S. Lin, G. Wang, Fabrication of carbon-coated NiO supported on graphene for high performance supercapacitors. RSC Adv. 6(17), 14199-14204 (2016). https://doi.org/10.1039/C6RA01405D

43. J.S. Park, J.S. Cho, Y.C. Kang, Scalable synthesis of $\mathrm{NiMoO}_{4}$ microspheres with numerous empty nanovoids as an advanced anode material for Li-ion batteries. J. Power Sources 379, 278 287 (2018). https://doi.org/10.1016/j.jpowsour.2018.01.050

44. Y. Zhu, H. Guo, Y. Wu, C. Cao, S. Tao, Z. Wu, Surface-enabled superior lithium storage of high-quality ultrathin $\mathrm{NiO}$ nanosheets. J. Mater. Chem. A 2(21), 7904-7911 (2014). https ://doi.org/10.1039/C4TA00257A

45. W. Huang, S. Ding, Y. Chen, W. Hao, X. Lai, J. Peng, J. Tu, Y. Cao, X. Li, 3D NiO hollow sphere/reduced graphene oxide composite for high-performance glucose biosensor. Sci. Rep. 7(1), 5220 (2017). https://doi.org/10.1038/s41598-017-05528 $-1$

46. G. Meng, Q. Yang, X. Wu, P. Wan, Y. Li, X. Lei, X. Sun, J. Liu, Hierarchical mesoporous $\mathrm{NiO}$ nanoarrays with ultrahigh capacitance for aqueous hybrid supercapacitor. Nano Energy 30, 831-839 (2016). https://doi.org/10.1016/j.nanoe n.2016.09.012

47. J.C. Groen, L.A.A. Peffer, J.P. Ramírez, Pore size determination in modified micro-and mesoporous materials. Pitfalls and limitations in gas adsorption data analysis. Micropor. Mesopor. Mater. 60(1-3), 1-17 (2003). https://doi.org/10.1016/S1387 $-1811(03) 00339-1$

48. G.D. Park, J.H. Kim, Y.J. Choi, Y.C. Kang, Large-scale production of $\mathrm{MoO}_{3}$-reduced graphene oxide powders with superior lithium storage properties by spray-drying process. Electrochim. Acta 173, 581-587 (2015). https://doi.org/10.1016/j. electacta.2015.05.090

49. Z. Bai, Z. Ju, C. Guo, Y. Qian, B. Tang, S. Xiong, Direct large-scale synthesis of 3D hierarchical mesoporous $\mathrm{NiO}$ microspheres as high-performance anode materials for lithium ion batteries. Nanoscale 6(6), 3268-3273 (2014). https://doi. org/10.1039/C3NR05676G

50. Z. Fan, J. Liang, W. Yu, S. Ding, S. Cheng et al., Ultrathin $\mathrm{NiO}$ nanosheets anchored on a highly ordered nanostructured carbon as an enhanced anode material for lithium ion batteries. Nano Energy 16, 152-162 (2015). https://doi.org/10.1016/j. nanoen.2015.06.009

51. J.S. Cho, J.M. Won, J.H. Lee, Y.C. Kang, Synthesis and electrochemical properties of spherical and hollow-structured $\mathrm{NiO}$ aggregates created by combining the kirkendall effect and Ostwald ripening. Nanoscale 7(46), 19620-19626 (2015). https:// doi.org/10.1039/C5NR05930E

52. L. Su, Z. Zhou, P. Shen, Ni/C hierarchical nanostructures with $\mathrm{Ni}$ nanoparticles highly dispersed in N-containing carbon nanosheets: origin of Li storage capacity. J. Phy. Chem. C 116(45), 23974-23980 (2012). https://doi.org/10.1021/jp310 $054 \mathrm{~b}$

53. J.K. Kim, J.H. Kim, Y.C. Kang, Electrochemical properties of multicomponent oxide and selenide microspheres containing Co and Mo components with several tens of vacant nanorooms synthesized by spray pyrolysis. Chem. Eng. J. 333, 665-677 (2018). https://doi.org/10.1016/j.cej.2017.09.169

54. L. Su, Y. Zhong, Z. Zhou, Role of transition metal nanoparticles in the extra lithium storage capacity of transition metal oxides: a case study of hierarchical core-shell $\mathrm{Fe}_{3} \mathrm{O}_{4} @ \mathrm{C}$ and Fe@ C microspheres. J. Mater. Chem. A 1(47), 15158-15166 (2013). https://doi.org/10.1039/C3TA13233A

55. J.S. Cho, J.S. Park, Y.C. Kang, Porous FeS nanofibers with numerous nanovoids obtained by kirkendall diffusion effect for use as anode materials for sodium-ion batteries. Nano Res. 10(3), 897-907 (2017). https://doi.org/10.1007/s1227 4-016-1346-9

56. J.S. Cho, S.Y. Lee, H.S. Ju, Y.C. Kang, Synthesis of NiO nanofibers composed of hollow nanospheres with controlled sizes by the nanoscale kirkendall diffusion process and their electrochemical properties. ACS Appl. Mater. Interfaces 7(46), 25641-25647 (2015). https://doi.org/10.1021/acsam i. 5 b08793

57. H. Tabassum, R. Zou, A. Mahmood, Z. Liang, Q. Wang et al., A universal strategy for hollow metal oxide nanoparticles encapsulated into B/N Co-doped graphitic nanotubes as highperformance lithium-ion battery anodes. Adv. Mater. 30(8), 1705441 (2018). https://doi.org/10.1002/adma.201705441

58. H. Wang, N. Mao, J. Shi, Q. Wang, W. Yu, X. Wang, Cobalt oxide-carbon nanosheet nanoarchitecture as an anode for highperformance lithium-ion battery. ACS Appl. Mater. Interfaces 7(4), 2882-2890 (2015). https://doi.org/10.1021/am508208c

59. J. Leng, Z. Wang, X. Li, H. Guo, H. Li, K. Shih, G. Yan, J. Wang, Accurate construction of a hierarchical nickel-cobalt oxide multishell yolk-shell structure with large and ultrafast lithium storage capability. J. Mater. Chem. A 5(29), 1499615001 (2017). https://doi.org/10.1039/C7TA02956J 